\title{
Assessing Ultra-Fine-Scale Factors to Improve Human West Nile Virus Disease Models in the Chicago Area
}

Johnny Uelmen ( $\square$ uelmen@illinois.edu )

University of Illinois at Urbana-Champaign https://orcid.org/0000-0003-3057-5107

Patrick Irwin

Northwest Mosquito Abatement District

William Brown

University of Illinois at Urbana-Champaign

Surendra Karki

University of Illinois at Urbana-Champaign

Marilyn O'Hara Ruiz

University of Illinois at Urbana-Champaign

Bo Li

University of Illinois at Urbana-Champaign

Rebecca Smith

University of Illinois at Urbana-Champaign

Research

Keywords: WNV, disease modeling, Culex, vector index, human illness

Posted Date: March 31st, 2020

DOI: https://doi.org/10.21203/rs.3.rs-19812/v1

License: (9) This work is licensed under a Creative Commons Attribution 4.0 International License.

Read Full License 


\section{Assessing Ultra-Fine-Scale Factors to Improve Human West Nile Virus Disease}

\section{Models in the Chicago Area}

$3 \quad{ }^{* 1}$ Uelmen, J.A., ${ }^{2}$ Irwin, P., ${ }^{1}$ Brown, W.M., ${ }^{1,3}$ Karki, S., ${ }^{1}$ Ruiz, M.O., ${ }^{4}$ Li, B., and ${ }^{1}$ Smith, R. L.

$4 \quad{ }^{1}$ University of Illinois at Urbana-Champaign, Department of Pathobiology, College of Veterinary Medicine,

52522 Veterinary Medicine Basic Sciences Building, 2001 South Lincoln Avenue, Urbana, IL 61802 USA

$6 \quad{ }^{2}$ Northwest Mosquito Abatement District, 147 West Hintz Road, Wheeling, IL 60090 USA

$7 \quad{ }^{3}$ Department of Epidemiology and Public Health, Himalayan College of Agricultural Sciences and

8 Technology, Kirtipur, Kathmandu, Nepal

$9{ }^{4}$ University of Illinois at Urbana-Champaign, Department of Statistics, Illini Hall, Room 101, 725 South

10 Wright Street, Champaign, IL 61820 USA

$11{ }^{*}$ Corresponding Author

12 Keywords: WNV, disease modeling, Culex, vector index, human illness

14 Abstract

15 Background: Since 1999, West Nile virus (WNV) has moved rapidly across the United

16 States, resulting in tens of thousands of human cases. Both the number of human cases

17 and the level of mosquito infection (MIR) vary across time and space and are related to

18 numerous abiotic and biotic forces, ranging from differences in microclimates to socio-

19 demographic factors. Because the interactions among these multiple factors affect the

20 locally variable risk of WNV illness, it has been especially difficult to model human

21 disease risk across varying spatial and temporal scales. Cook and DuPage Counties,

22 comprising the city of Chicago and surrounding suburbs, are among the areas hardest hit

23 by WNV in the United States. Despite active mosquito control efforts, there is consistent

24 annual WNV presence, resulting in more than 285 confirmed WNV human cases and 20

25 deaths in the past 5 years in Cook County alone. 
26 Methods: A previous WNV model for the greater Chicago area identified the fifty-five

27 most high and low risk study areas in the Northwest Mosquito Abatement District

28 (NWMAD), an enclave $1 / 4$ the size of the previous study area. In these locations, human

29 WNV risk was stratified by strength of predictive success, as indicated by differences in

30 studentized residuals. Within these areas, an additional two-years of field collections and

31 data processing was added to a 10-year WNV dataset and assessed by an ultra-fine-scale

32 multivariate logistic regression model.

33 Results: Multivariate statistical approaches revealed that this ultra-fine-scale model

34 resulted in fewer explanatory variables while improving upon the fit of the existing

35 model. Beyond mosquito infection rates and climatic factors, efforts to acquire additional

36 covariates only slightly improve model predictive performance.

37 Conclusions: These results suggest human WNV illness in the Chicago area may be

38 associated with fewer, but increasingly critical, key variables at finer scales. Given

39 limited resources, this study suggests a large variation in the significance to model

40 performance, and provides guidance in covariate selection for optimal WNV human

41 illness modeling. 


\section{Introduction}

43 In December of 1937 in Northern Uganda, a 37-year-old woman became ill with a fever

44 of $100.6^{\circ} \mathrm{F}$ (Smithburn et al. 1940). She would later become the first documented human

45 infected with the West Nile virus (WNV; Family Flaviviridae), a mosquito-borne disease

46 originating from the West Nile region of Uganda. WNV first arrived to the United States

47 (U.S., New York, NY) in 1999, most likely via a hitchhiking infected mosquito in an

48 airline wheel well (Hadfield et al. 2019). This newly introduced WNV strain matched the

49 Isr98 strain, isolated from a single goose in Israel in 1998 (McLean et al. 2002). Once

50 arriving in New York, the virus took only three years to traverse the contiguous U.S.,

51 reaching California in 2002 (Sejvar 2003). The virus has now become one of the most

52 widespread arboviruses in the world, and is present in every continent except Antarctica

53 (Kramer et. al. 2008).

54 In the Midwestern U.S., mosquitoes of the Culex $(C x$. genus are the main vectors for

55 transmitting WNV (Goddard et al. 2002). Culex mosquitoes are capable of feeding on

56 several hosts to satisfy one blood meal, increasing the opportunity for multiple infections

57 across species (Hamer et al. 2009). Although primarily ornithophilic, prior studies

58 indicate that $C x$. species may shift feeding preferences to humans later in the summer

59 months (Russell and Hunter 2012); (Kilpatrick et al. 2006). Humans and other mammals,

60 most notably horses, are considered “dead-end" hosts, not capable of producing sufficient

61 levels of viremia to subsequently infect biting mosquitoes (Bowen and Nemeth 2007).

62 From 1999-2018, there have been a total of 50,830 human cases resulting in 2,330

63 deaths across the US (Centers for Disease Control (CDC) 2019). In many cities and states

64 that experience high WNV incidence, there are efforts in place to control mosquito 
65 populations. However, despite these methods, WNV continues its epizootic and enzootic

66 cycles year to year, and large-scale outbreaks have occurred in the years 2002, 2003,

67 2012, and 2018 across the United States (citation?). At local scales, drivers of human

68 disease, including WNV, vary in actual effect and magnitude from that observed on state,

69 regional, or national scales. Previous studies have identified common abiotic and biotic

70 factors associated with human WNV illness, including prior weather conditions (weekly

71 temperature and precipitation lags), mosquito infection and abundance, socio-

72 demographic characteristics of the local population, and level of public awareness and

73 education, but these were all at state or regional scales (Ruiz et al. 2004; Kilpatrick and

74 Pape 2013; Manore et al. 2014; Roiz et al. 2014; Rosà et al. 2014; Wimberly et al. 2014;

75 Hahn et al. 2015; Giordano et al. 2017).

76 Karki et al. (2019) is one of the few studies to evaluate weekly spatiotemporal factors

77 and their associations with human WNV illness at a smaller scale, in a highly urban 2-

78 county area (Cook/DuPage counties) that includes the greater Chicago, IL area. This

79 region consistently experiences one of the highest annual WNV incidences in the country.

80 The previous study incorporated among the finest temporal and spatial scales known to

81 date, using 1-km hexagon grids to minimize biases from political boundaries. While an

82 excellent overall model fit was achieved by using a large number of explanatory variables,

83 the relative importance of covariates and the resulting disease prediction across mico-

84 scales is still not understood.

85 The Northwest Mosquito Abatement District (NWMAD), occupying the northwest

86 corner of Cook County, is one of Chicago's four abatement districts responsible for

87 mosquito control, and has an excellent long-term mosquito abundance and testing data 
88 throughout its jurisdiction. This study targeted fifty-five individual 1-km hexagons within

89 the NWMAD for an ultra-fine-scale (UFS) assessment of human WNV illness spatio-

90 temporal variability in suburban environments. Specifically, this study's main objectives

91 were to: (i) evaluate and contrast key variables in this study to the larger Cook/DuPage

92 model, (ii) assess the similarities and differences among locations that were predicted

93 accurately by the larger model and those that were predicted poorly, (iii) quantify the

94 impact of newly acquired data on prediction of human WNV illness, and (iv) determine if

95 vector index is a stronger predictor than the additive effects of MIR and mosquito

96 abundance. Ultimately, this study aims to highlight how WNV disease variance may be

97 better captured at finer spatio-temporal scales. The results of this study will provide

98 future researchers, public health agencies, and abatement districts essential details and

99 suggestions for improving WNV prediction and optimizing efficiency of targeted

100 mosquito control efforts.

101 2. Methods

102 This project was approved by the Institutional Review Board of the University of

103 Illinois at Urbana-Champaign, the Illinois Department of Public Health (IDPH), and the

104 University of Illinois Biosafety Committee. Human case data were provided by IDPH

105 without any personal identifying information.

1062.1 Study area

107 This study was conducted within the NWMAD, a $605-\mathrm{km}^{2}$ area that comprises the 108 northwest suburbs of Chicago (Cook County, IL, Figure 1). As described in Karki et al.

109 (2019), all model data were summarized and processed within 1-km diameter hexagons, 110 as a neutral configuration in both size and shape, free of any political boundaries. Using 
111 statistical selection processes (described below), fifty-five of the 1,019 hexagons within

112 the NWMAD were selected as the observational units for this study.

\subsection{Model covariates}

114 The Cook/DuPage model evaluated forty covariates derived from a variety of abiotic

115 and biotic factors, including climate and weather records, mosquito infection, socio-

116 demographic census data, and other biological conditions (described below). For this

117 study, additional data processing and field collections resulted in forty-two additional

118 non-collinear independent variables (Table 1). Each variable was independently

119 calculated by hexagon for CDC epidemiological weeks 18-38 (Sunday-Saturday) of the

120 years 2005 through 2016 (CDC 2019).

$121 \quad \underline{2.2 .1}$ Previously existing data

\section{$122 \quad$ 2.2.1a Human illness}

123 Human WNV cases in Illinois were classified as either confirmed ${ }^{1}$ or probable $^{2}$, as

124 reported to the IDPH by public health or licensed medical professionals (mandatory

125 reporting of WNV cases is required in the state). We recognize that exposure to

126 mosquito-borne disease occurs often and in many locations. Confirming the moment an

127 infected mosquito inoculates a human is nearly impossible to document. Therefore, we

128 assumed human cases were exposed to WNV at their home addresses. The latitude and

129 longitude point locations were provided to the third decimal degree and aggregated to

\footnotetext{
${ }^{1}$ The case definition for a confirmed case of arboviral encephalitis in Illinois is a clinically compatible illness that is laboratory confirmed at a public health laboratory. The laboratory criteria are a fourfold or greater rise in serum antibody titer; or isolation of virus from, or demonstration of viral antigen in, tissue, blood, CSF or other body fluid; or specific IgM antibody in CSF.

${ }^{2}$ A probable case of arboviral encephalitis is a clinically compatible illness occurring during the season when arbovirus transmission is likely to occur and with the following supportive serology: a stable (twofold or smaller change) elevated antibody titer to an arbovirus, e.g., $>320$ by hemagglutination inhibition, $>128$ by complement fixation (CF), $>256$ by IF, $>160$ by neutralization, or a positive serologic result by enzyme immunoassay (EIA) or MAC ELISA.
} 
130 the hexagon level for analytical and display purposes. Human cases were converted into

131 binary form (presence/absence of illness) and weekly case rate, controlling for human

132 population, for each hexagon. Use of human case data was approved by the University

133 of Illinois Institutional Review Board and the Illinois Department of Public Health.

$134 \quad$ 2.2.1b Abiotic Predictors

135 Land Cover: The 2011 United States Geological Survey (USGS 2011) National Land

136 Cover Database (NLCD) provided $30 \mathrm{~m}$. resolution classified raster data for the

137 NWMAD. The raster comprising NWMAD was clipped, extracted, and tabulated by

138 landscape code using the tabulate area tool in ArcGIS 10.5.1 (Environmental Systems

139 Research Insititute 2011). There were 15 unique land cover types: forests (deciduous,

140 evergreen, and mixed), urban (developed open space, developed low intensity, developed

141 medium intensity, and developed high intensity), open water, herbaceous wetlands,

142 cultivated crops, wetlands (woody and herbaceous), grassland, barren land, and shrubs.

143 Proportions of each type within each hexagon were calculated using the $30 \mathrm{~m}$. raster

144 resolution.

145 Weather: Daily mean temperature and precipitation were acquired from the PRISM

146 Climate Group (Oregon State University 2019), provided as 4-km resolution grids.

147 Weekly mean temperatures were calculated by taking the average of each of the seven

148 days of the week, whereas weekly precipitation totals were calculated as a sum of each of

149 the seven days of the week. As a proxy for winter temperature, the monthly average for

150 each January from 2005-2016 was also calculated. Using the zonal statistics as table

151 function in ArcGIS, each mean temperature and precipitation value was extracted for

152 each hexagon in this study. 
154 Mosquito infection: All mosquito infection data were acquired from the Illinois

155 Department of Public Health (IDPH), the state agency responsible for collecting and

156 maintaining standardized mosquito collection and testing data. Mosquito infection is

157 defined as the minimum infection rate (MIR), calculated by the following equation:

$158 \quad \frac{\# \text { of positive mosquito pools }}{\text { total specimens tested }} \times 1000$,

159 where a mosquito pool in this analysis consisted of up to 50 female Culex mosquitoes

160 that were collected by the same trap. A vast majority of the tests used to identify the

161 presence of WNV was the Rapid Analyte Measurement Platform (RAMP), although

162 some mosquito pools were also tested by Real Time reverse transcriptase polymerase

163 chain reaction (RT-PCR) or VecTest.

164 Trap locations were provided by the IDPH. Whenever precise spatial locations were not

165 available, the existing address on file was used to generate a geocoded trap location. The

166 MIR values for each trap were calculated and interpolated across the NWMAD by

167 inverse distance weighting (IDW) in ArcGIS. The average MIR values were extracted for

168 each hexagon by using the zonal statistics as table function in ArcGIS.

169 Demographic: Total population and racial composition (White, African American,

170 Hispanic, and Asian) at the census block level were extracted from the 2010 U.S. Census

171 then converted as a percentage for each hexagon. Additionally, age of housing (built

172 before 1940, 1940-1969, 1970-1989, and post 1990) and income were averaged for each

173 hexagon using data provided by 2015 American Community Survey. These data were

174 processed in ArcGIS using the intersection tool.

$175 \quad 2.2 .2$ Newly added data 
177 Catch basin (e.g. sewer) density: The NWMAD provided point data for each catch basin

178 within its jurisdiction. All point data was then aggregated to each hexagon using the

179 spatial location join feature in ArcGIS. A combined total of 8,443 catch basins were

180 recorded among all hexagons $(\min =1, \max =543)$.

181 Size and distribution of commercial and residential lots and buildings: High-resolution

182 (1 m.) aerial imagery from ArcGIS and USDA (2018) were used as a basemap for each

183 hexagon. Each permanent structure (e.g. residence, shed, garage, deck) was traced and

184 converted to polygons in ArcGIS. The area and perimeter of each polygon was calculated

185 and aggregated for each hexagon. Commercial and residential lots were provided by

186 Cook County Data Catalogy (2019), using 2016 tax appropriations. In total, there were a

187 combined 22,892 lots with 24,468 buildings or permanent structures.

188 Light pollution: Radiation from light pollution was provided by the New World Atlas of

189 Artificial Night Sky Brightness (Falchi, F., Cinzano, P., Duriscoe, D., Kyba, C. C. M.,

190 Elvidge, C. D., Baugh, K., Portnov, B., Rybnikova, N. A., Furgoni 2016a, 2016b). Light

191 pollution was acquired from 2014 data of the VIIRS DNB sensor on the Suomi National

192 Polar-orbiting Partnership (NPP) satellite. Pixel resolution was $0.75 \mathrm{~km}$; mean value for

193 each 1-km hexagon was calculated in ArcGIS.

$194 \quad$ 2.2.2b Biotic Predictors

195 Historical mosquito abundance: The NWMAD consistently collected and diligently

196 maintained their mosquito trapping and identification data throughout the study period.

197 Once deployed, traps were usually checked at least twice a week. Over the 2005-2016

198 study period, there were a total of 59 traps used in the NWMAD, resulting in a total of 
19948,406 female $C x$. spp. from 22 light traps, and 1,110,024 from 37 gravid traps. Weekly

200 mosquito collections by trap were geocoded and interpolated across all hexagons via

201 IDW and extracted using the zonal statistics as table function for each hexagon in ArcGIS

202 10.5.1. Mosquito abundance was calculated as the weekly cumulative number of captured

203 female Culex spp. from each respective gravid trap (GT) and light trap (LT). Since early

204 trap data did not reliably identify mosquitoes to species, all $C x$. spp. values were pooled.

205 However, prior studies from Chicago region indicated that $C x$. pipiens and $C x$. restuans

206 are the major $C x$. species present in this area. Normalized Difference Vegetation Index

207 (NDVI): To evaluate the magnitude of all vegetation, NDVI was incorporated by

208 hexagon, recorded as an average value at three timepoints of each year: CDC

209 epidemiologic weeks 21 ( $3^{\text {rd }}-4^{\text {th }}$ week of May), 28 ( $2^{\text {nd }}-3^{\text {rd }}$ week of July), and 35 ( $4^{\text {th }}$

210 week of August- $1^{\text {st }}$ week of September). These CDC epidemiologic weeks mark the

211 center of each the three 8-week active WNV periods in the Midwest, represented as T1 =

212 low WNV activity, $\mathrm{T} 2$ = high WNV activity, and T3 = moderate WNV activity. The best

213 available Landsat 7 or 8 bands for each respective time period were acquired from

214 EarthExplorer (USGS 2019) and processed in ArcGIS 10.5.1.

215 Human exposure during crepuscular time periods: Human activity observations were

216 conducted in public spaces inside each hexagon, during the crepuscular hours between 6-

$2179: 30 \mathrm{pm}$, the preferred feeding period for Cx. pipiens/restuans. Observations were

218 conducted within each hexagon for a total of ten minutes per visit. Specifically, a

219 researcher remained stationary for 2 minutes, walked 2 minutes, remained stationary in

220 the new position for 2 minutes, walked back to origination point for 2 minutes, then

221 remained stationary in the original position for 2 final minutes. Human exposure was 
222 determined as any period in time a person was outside of any building, vehicle, or

223 enclosed dwelling during the observation period. Observations were classified by

224 apparent gender and age (child, adult, or senior citizen).

225 Human Landing Catches: During human observations, another researcher collected

226 human-seeking mosquitoes via the human landing catch (HLC) method at the same

227 location. Each HLC visit exposed the researcher for fifteen minutes. To mitigate actual

228 biting events, the researcher would expose only one limb (arm or leg) at a given time.

229 Any mosquitoes that landed would be collected via mechanical aspirator and transferred

230 to a collection vial. All collected mosquitoes were transported to the NWMAD within 2

231 hours and stored at $-80^{\circ} \mathrm{C}$. All mosquito specimens were identified to species within three

232 days. Any mosquitoes identified as Culex spp. were sent to the Fritz Lab at the University

233 of Maryland for species confirmation by $C x$. pipiens group-specific primers via PCR.

234 Vector Index: The vector index (VI) was calculated as an estimate of the relative number

235 of WNV-infected mosquitoes. Specifically for this study, VI was calculated as the

236 average number of pooled Culex spp. collected per trap-week multiplied by the

237 proportion of mosquitoes infected with WNV. The following equation was modified from

238 the CDC (2013):

$$
\text { VI }=\sum_{i=\text { Culex spp.(pooled) }} \bar{N}_{i} \widehat{P}_{l} \text {, }
$$

240 where $\bar{N}_{i}=$ average density (number of mosquitoes per trap week) and $\hat{P}_{i}=$ estimated

241 MIR (proportion of mosquito pools testing positive for WNV). Calculated weekly VI for

242 each trap by week was then interpolated via IDW method for estimations across the

243 NWMAD. 
244 Nuisance Factor and Human WNV Added Risk: Mosquitoes collected via HLC methods

245 were categorized into one of two types: nuisance and WNV vectors. Since the majority of

246 mosquitoes collected were non-Culex, a quantitative index, nuisance factor, was created

247 to provide a risk spectrum of encountering nuisance mosquitoes in a given hexagon. The

248 following equation defines the nuisance factor:

$$
\text { Nuisance Factor }=\frac{\frac{\text { Human Observations }}{\text { Hour }} * \frac{\text { Nuissance Mosquitoes }}{\text { Hour }}}{100}
$$

250 Nuisance factor values ranged from a low of 0 to a high of 32.3 . To quantitatively

251 estimate potential risk for exposure to disease within a given hexagon, the human WNV

252 added risk factor was also created. This index is defined by the following equation:

$$
\text { Human WNV Added Risk }=\frac{\frac{\text { Human Observations }}{\text { Hour }} * \frac{\text { Culex spp. }}{\text { Hour }}}{100}
$$

254 Human WNV added risk ranged from a low of 0 to a high of 1.44.

\section{$255 \quad 2.3$ Statistical methods}

$256 \quad$ 2.3.1 Location selection

257 Of the total 1019 hexagons within the NWMAD, we selected fifty-five $(5.4 \%)$ as the

258 maximum number of sites that our research team could visit for fifteen minutes each,

259 weekly. The subset of fifty-five hexagons were selected based on two criteria: (1) the size

260 of the human population was $>0$, and (2) where the previous Cook/DuPage model either

261 predicted human WNV extremely well or extremely poorly, as determined by the 2005-

2622016 average residual output. Furthermore, the residual output was stratified by those

263 locations that had or had not experienced a human case during the 12 -year period. These

264 processes created a performance spectrum consisting of five categories of hexagons:

265 negative residuals without a human case (NR0), low residuals without a case (LR0), low 
266 residuals with a case (LR1), positive residuals without a case (PR0), and positive

267 residuals with a case (PR1) (Table 2). No hexagons with negative residuals in the

268 Cook/DuPage model had experienced a human case. The spatial arrangements of these

269 hexagons provide adequate coverage of the NWMAD's jurisdiction (Figure 2).

$270 \quad$ 2.3.2 Model Selection

271 Two seasons of field collections and processing of new data provided the UFS model

272 with an additional 42 covariates not made available in the previous Cook/DuPage model.

273 The generation of linear and logistic regression models began with a two-step selection

274 process for the initial covariate inclusion: (1) conduct a univariate analysis with each

275 predictor (independent variable) to the WNV disease outcome (binary $=$ logistic, case rate

$276=$ linear, dependent variable). Candidate variables for multivariate analysis were selected

277 using slightly more conservative p-value than Bursac et al. (2008), p-value $\leq 0.20$ vs. $\leq$

278 0.25). Models that create cut-off values of $p$-value $\leq 0.1$ for purposeful univariate

279 covariate selection can erroneously prevent important variables from entering final

280 models (Bendel and Afifi 1977; Greenland and Mickey 1989); (2) the final model, a

281 generalized linear model personality with a Poisson distribution and probit link function,

282 was selected using forward selection method, selecting the final model based on the

283 Bayesian information criterion (BIC). Non-significant covariates were removed from the

284 final model as a product of the iterative selection process. Secondarily, a receiver

285 operating characteristic (ROC) curve was used to visualize overall model performance

286 and Area Under the Curve (AUC) was calculated. All predictors were evaluated for

287 multicollinearity using the PROC REG procedure (SAS Institute Inc. Cary, NC, USA).

288 Regression analyses were analyzed using the Fit Model feature in JMP 14.2.0 (SAS 
289 Institute Inc. Cary, NC, USA). Binary WNV case outcome was analyzed with as a

290 nominal logistic personality. The continuous WNV case rate outcome was analyzed as a

291 standard least squares personality.

\section{$292 \quad$ 2.3.3 Model Comparisons}

293 Human WNV illness in the NWMAD was assessed under four model environments,

294 each expressing a defined set of specific parameters. The four model environments were:

295 1. MIR \& Mosquito Abundance (contains no VI covariates),

296 2. Vector Index (contains no MIR or mosquito abundance covariates),

297 3. Best-Fit (best fit with all covariates in respective assessment), and

298 4. Global (all covariates made available in respective assessment)

299 As a comparison, the original Cook/DuPage model was fit using only the 40 covariates

300 included in the final model fit from Karki et al. (2019). Each of these four model

301 environments were assessed using four different covariate sets:

302 1. All covariates (82 available covariates),

303 2. Excluding HLC and human observations covariates (74 available covariates),

3043 . Force-fitting HLC and human observations covariates ( 8 forced covariates, 82

$305 \quad$ available covariates), and

306 4. Only the covariates made available to the Cook/DuPage 2019 model (control

307 model, 40 available covariates).

308 Under each model environment and covariate set, the outcome of human WNV illness

309 was analyzed using:

310 1. Logistic regression (presence/absence human WNV illness) and

3112 2. Linear regression (WNV case rate) methods. 
312 In total, there were 36 models assessed; models are named using the convention $\mathrm{E}_{\mathrm{x}} \mathrm{C}_{\mathrm{y}} \mathrm{O}_{z}$,

313 where $\mathrm{x}$ is the model environment number $(0-4$, with number 0 assigned to the control

314 environment), $\mathrm{C}$ is the covariate set number (1-4), and $\mathrm{O}$ is the outcome number (1-2).

315 For both logistic and linear regression, each of the four model environments was fit using

316 each of the four covariate sets. In addition, the control models using only the covariates

317 from the final Cook/DuPage model applied to the UFS region were fit with and without

318 force fitting HLC and human observation covariates.

319 Half of the models were assessed under logistic and linear outcomes, respectively, and

320 based on the \# of Significant Covariates (quantity of variables included in final model

321 with $\mathrm{p}<0.05$ ) and Degrees of Freedom (the number of values in the final model that are

322 free to vary). Overall model performance was determined by BIC. While BIC and

323 Aikake's Information Criterion (AIC) are both maximum likelihood estimators, BIC was

324 chosen to determine model strength due to its stronger penalty term for covariate

325 inclusion (Schwarz 1978).

$326 \quad$ 2.3.4 Covariate Performance

327 Similarly to the model performance index, to evaluate the performance for all covariates

328 across 18 logistic and 18 linear models, each of the 82 covariates were standardized by

329 creating the following index:

$$
\bar{p}_{\text {Covariate }}=\frac{\text { Significance Level }}{\text { Data Availability }}
$$

331 where: Significance Level = significance level of covariate in each of the 36 final models

$332(\mathrm{p}<0.001=4, \mathrm{p}<0.01=3, \mathrm{p}<0.05=2$, included in the final model $=1)$, and Data

333 Availability $=$ tradeoff between resources required to acquire a respective covariate (level

3341 = data widely available, no processing needed, level $2=$ data available, requires 
335 minimal to moderate processing/analyses, level $3=$ data available, requires extensive

336 processing/analyses, level 4 = data not available, needs to be collected, processed, and

337 analyzed, Table S1). The final net prediction:availability tradeoff used to create the Data

338 Availability variable are categorical and based on the authors' personal experiences with

339 data used in this study.

$340 \quad 3$. Results

3413.1 Location Description

342 The UFS study area contained a total of forty humans WNV cases from 2005-2016

343 (Table 2).

$344 \quad 3.2$ Model Fitting

345 With the exception of model $\mathrm{E}_{4} \mathrm{C}_{3} 0_{1}$, all models successfully converged (Tables 3 and 4),

346 with AUC for the logistic models ranging from 0.84 to 0.97 and BIC values of 576 to 769 ,

347 while BIC values for linear regression models ranged from -227444 to -181982. Despite

348 converging, all global models $(\mathrm{n}=8)$ were excluded from the analysis due to statistical

349 overfitting.

$350 \quad 3.2$ Model Comparison

351 The highest performing WNV human risk models were $\mathrm{E}_{3} \mathrm{C}_{4} \mathrm{O}_{3}(\mathrm{Cook} / \mathrm{DuPage}$ Best Fit,

$352 \mathrm{df}=8, \mathrm{BIC}=-227444)$ and $\mathrm{E}_{2} \mathrm{C}_{4} \mathrm{O}_{1}(\mathrm{Cook} /$ DuPage $+\mathrm{VI}, \mathrm{df}=14, \mathrm{BIC}=576.2)$, for linear

353 and logistic regressions, respectively (Tables $3 \& 4$ ).

354 The top five models that predicted human WNV cases strongest were represented by the

355 control $\left(\mathrm{E}_{0}, \mathrm{n}=2\right)$, best-fit $\left(\mathrm{E}_{3}, \mathrm{n}=2\right)$ and vector index $\left(\mathrm{E}_{2}, \mathrm{n}=1\right)$ environments (Figures 3B,

356 Table 5). These models' corresponding covariate sets were represented by variables only 
357 available to the original Cook/DuPage models $\left(\mathrm{C}_{4}, \mathrm{n}=4\right)$, and force-fitting HLC

358 covariates $\left(C_{3}, n=1\right)$ environments.

3593.3 Covariate Performance

360 Of the 82 available covariates, $70(85.4 \%)$ were included at least once among a given

361 model, excluding the overfit global models. Of the 41 covariates $(58.6 \%)$ that were

362 greater than the mean covariate performance, seven were highly efficient (determined by

363 natural break in the distribution), providing a crude estimation as most valuable variables

364 for human WNV estimation (Figure 3A). These covariates are provided here in

365 descending order of most importance: tempc (temperature $\left.\left({ }^{\circ} \mathrm{C}\right), \bar{p}=1.15\right)$, preci

366 (precipitation (mm.), $\bar{p}=1.14$ ), $\operatorname{Yr}($ year, $\bar{p}=1.0$ ), templag3 (temperature lagged by 3

367 weeks, $\bar{p}=0.92$ ), blpct (barren land (\%), $\bar{p}=0.92$ ), precilag1 (precipitation lagged by 1

368 week, $\bar{p}=0.90$ ), and VIlag4 (vector index 4 weeks prior, $\bar{p}=0.88$ ). All eight HLC and

369 human observation covariates were included in a final model, but none performed highly

$370\left(\bar{p}_{\text {each HLC Covariate }}=0.25\right)$. Estimates and calculations for individual covariates are available

371 in Additional file 1.

372 The eight HLC and human observation covariates provided significant differences in

373 observations and mosquito collections by hexagon type (Figure 4A \& 4B). The indices,

374 nuisance mosquito exposure and human WNV added risk, significantly differed by

375 hexagon type (Figure 4C). Hexagons designated as PR1 (positive residual

376 (underpredicted actual cases) with a prior human WNV case) were found to have the

377 most human observations and collected mosquitoes (from both Culex and non-Culex

378 spp.) per visit. This combination of factors provides hexagons among the PR1 type as the 
379 most "risky" in regard to human WNV added risk and increased nuisance mosquito

380 exposure (Figure 5).

\section{4. Discussion}

382 With the exception of $\mathrm{E}_{0} \mathrm{C}_{4} \mathrm{O}_{2}$, the Cook/DuPage control models, in conjunction with all

383 other covariate and outcome sets, were consistently ranked moderate to low in WNV

384 predictability and net value. Despite excellent prediction capabilities for the larger

385 Cook/DuPage counties study area, this finding suggests that the UFS study areas have

386 more variance from unaccounted sources that are missed or oversimplified in traditional,

387 large-scale models.

388 In addition to model comparisons, this study evaluated the performance of the newly

389 acquired VI in comparison to the previously used MIR in combination with mosquito

390 abundance. The original Cook/DuPage model only used MIR and its associated 4-week

391 lags and achieved very good prediction results over the 2-county area. Overall, when fit

392 to the UFS study area, adding mosquito abundance and associated 4-week lags improved

393 this model. When evaluating WNV prediction as a linear outcome, the best-fit model

394 using only covariates available to the original Cook/DuPage model was the highest

395 performing in WNV predictability. However, when evaluating WNV prediction as a

396 binary outcome, VI (a product of MIR and abundance together) and its associated 4-week

397 lags replaced MIR as the best predictor of human WNV. While no model emphasizing

398 MIR and abundance was selected as one of the best predictive models, at least one of

399 these variables (and their associated lags) were represented in 4 of the 5 best models

400 (control and best-fit, $\mathrm{n}=2$ for each model). On the contrary, VI, as an emphasized model

401 environment, was selected as the best performing logistic model. Both MIR and VI are 
402 critical components in predicting WNV. Deciding between the two biological indicators

403 will be largely dependent upon the data availability for each model of interest. However,

404 if resources are limited, the net model value leans in favor of using MIR.

405 The addition of 42 new covariates required a significant allocation of resources but

406 provided minimal benefits towards reducing variance in human WNV prediction.

407 Fortunately, this study suggests that excellent disease prediction models can be achieved

408 with conventional covariates that are publicly available, requiring little to no processing

409 and/or analyses (data availability scores $\leq 2$, Figure 3B). However, any covariate used

410 should be adjusted and properly designed for the highest spatial and/or temporal

411 resolution possible, which may require additional efforts to accomplish.

412 Extensive review of literature indicated no other studies have evaluated covariate

413 strength given limited resources, particularly in the context of making decisions to

414 acquire data. Therefore, the categorizations of covariates by resource allocation (values

415 ranging from 1 (low) to 4 (high)) are based on the experiences of the authors during this

416 study. These values are subjective and may vary across institution or research group, but

417 they may be used as a general estimation in model selection and decision-making. For

418 example, variables related to building and lot size (avg bldg. area: avg lot area, bldg.

419 footprint area avg, bldg. footprint area total, bldg. footprint peri avg., bldg. footprint peri

420 total, and total bldg. area: total lot area) were all ranked a value of 4 because of extensive

421 data processing and review. The authors downloaded high resolution, cloud-free satellite

422 images that were used as a basemap for digital tracing of every building structure (houses,

423 businesses, sheds, detached garages, storage units, etc.) and lots (residential and

424 commercial). This resulted in $>47,000$ structures and lots digitally traced manually. On 
425 the other hand, weather variables (e.g. preci, tempc) were ranked a value of 1 because

426 very little resources were devoted to have the data in a "ready" state. The source of these

427 data, PRISM Climate Group, allows for monthly summaries to be downloaded and

428 extracted with one quick geostatistic process.

429 This study also aimed to address a key missing index that few studies have evaluated:

430 the relationship of human activity, mosquito exposure, and WNV disease risk. While the

431 related variables did not greatly impact overall model strength, they did provide key

432 insight into a potential key in WNV ecology - the areas that were previously

433 underpredicted with recorded human WNV (hex type: PR1) were consistently found to

434 have the most human activity at crepuscular times, the most mosquitoes overall, and the

435 most Culex mosquitoes. However, our results appear to contradict the findings of Read et

436 al. (1994), who discovered that as reports of biting nuisance mosquitoes increased beyond

4372 per minute, outdoor human activity rapidly declined. Our results indicate that as

438 mosquito collections increased, human observations also increased (Figure 4). Not only is

439 this a potentially dangerous combination that can foster environments ideal to mosquito-

440 human spillover, previous modeling efforts failed to capture these cases. Future

441 directions will target these highly susceptible locations and aim to capture any additional

442 unaccounted variance.

443 Like all disease modeling efforts, there are always reporting biases that directly affect

444 true case prevalence. Unfortunately, many vector-borne diseases are largely

445 underreported (Bowden et al. 2011, Nelson et al. 2015, Waterman et al. 2015, CDC 2018),

446 as human cases are vastly overlooked or misdiagnosed, largely due to low severity in

447 disease manifestation in a majority of cases (CDC 2015, Rosenberg et al. 2018). This 
448 creates difficulties in predicting when and where VBD incidence will arise. In the

449 Chicago area, models in both the UFS and Cook/DuPage locations have very good

450 human WNV prediction capabilities. Despite having among the highest total number of

451 human WNV cases in the U.S. (CDC National arboviral surveillance system (ArboNET,

452 CDC 2020)), this region has more observational units denoted as non-cases than cases.

453 That has resulted in models with excellent accuracy in predicting where there are no

454 human cases, thus inflating the true accuracy of our models. Nonetheless, while our

455 models are able to reliably predict where human cases are present, the magnitude of

456 effect can be missed (e.g. "hot spots" with greater than 1 case may not be represented).

457 Disease modelers need to be cognizant of saturating their efforts, both statistically and

458 biologically. Statistically, additional and meaningful covariates will usually improve

459 model fit parameters. However, the inclusion of too many variables can result in

460 overfitting, resulting in models failing to converge (Babyak 2004, Hawkins 2004, Lever

461 et al. 2016). It is estimated that about $80 \%$ of human WNV infections are unreported, as

462 clinical signs are minor or asymptomatic (CDC 2010, Petersen, Brault, et al. 2013). The

463 remaining $20 \%$ of humans develop West Nile fever, and among this group, about $1 \%$ will

464 develop severe and sometimes fatal neuroinvasive disease. It is possible that no matter

465 the amount of effort to improve model fit, there is an element of variability attributed

466 with infected humans not seeking medical attention and thus, reducing true disease

467 prevalence (Petersen, Carson, et al. 2013).

468 Overall, when compared to the Cook/DuPage model, the best UFS models required

469 fewer predictors and produced a stronger overall fit using most, if not all, the same

470 covariates made available to both model types. Spending the resources (time, money, 
471 human-power, processing, analyses, logistic, etc.) to acquire additional covariates may

472 not necessarily be worth the impact on improving human WNV modeling predictions.

473 Rather, fine-tuning the traditional covariates (climatic, weather, and MIR, for example),

474 to the highest spatiotemporal resolution possible may be the most efficient use of

475 resources to minimize variance in VBD prediction models. 


\section{Key Takeaways}

477 1. The factors and their overall effect on the prediction of human WNV cases differs across scale. Although improved, in comparison to the control Cook/DuPage model applied to the same study region, the "best fit" UFS model AUC $=0.89$, suggesting newly unaccounted variances are present.

2. Both vector index and MIR contribute to high performing human WNV prediction models under UFS study areas. In direct comparison, VI is favorable to MIR. However, given limited resources in acquiring and processing additional data, MIR is more efficient for predicting human WNV illness.

3. The effort and resources required to acquire additional covariates, most of which are not publicly available, demonstrate a slight improvement in model prediction and appear less important in reducing variance.

4. In addition to the conventional WNV covariates, namely weather and infection rates, land-use and land-cover and SES/demographic information are widely available with little to no processing or analyses required, and provide the breadth to develop excellent prediction models. However, any covariate utilized must be structured at the finest spatial and/or temporal resolution possible.

493 5. Human exposure to mosquito biting rates provided minimal benefits to model prediction. More importantly however, these two covariates provided potentially key insight to the susceptibility of humans in locations where WNV is prevalent. Additionally, where WNV is less of a concern, these results provide insight into nuisance mosquito exposure that may lead to improvements in targeted control efforts. 


\section{Declarations}

500 Acknowledgements

501 The authors would like to thank Roger Nasci for providing expert insight in vector

502 biology and modeling efforts, Dan Bartlett for providing geospatial data and detailed

503 field information, the Megan Fritz lab for providing confirmatory Culex identification,

504 and Chris Stone and Andrew Mackay from the Illinois Medical Entomology lab for

505 providing guidance and expertise with human landing catch methodology.

506 Ethics Statement

507 All data collected from the IDPH were through a user agreement. The human activity

508 observation protocol was approved by the University of Illinois Institutional Review

509 Board. Field collections and any use of generated data were approved by the University

510 of Illinois Biosafety Committee.

$511 \quad$ Availability of Data and Materials

512 The dataset supporting the conclusions of this article is available in the [repository name]

513 repository, [unique identifier and hyperlink to dataset in http://format].

514 Authors' contributions

515 JAU conceived the presented idea, collected field samples and provided data analysis and

516 processing. PI provided research assistance and expertise in mosquito collection and

517 biology. SK provided expertise and additional datasets for analysis. WMB provided

518 analytical assistance and provided data sources. BL provided statistical oversight and

519 expertise. MOR provided the initial product idea, planning, and supervision. RLS

520 provided oversight of all aspects throughout the study. All authors discussed the results

521 and contributed to the final manuscript. 


\section{$522 \quad$ Funding}

523 This publication was supported by Cooperative Agreement \#U01 CK000505, funded by

524 the Centers for Disease Control and Prevention. Its contents are solely the responsibility

525 of the authors and do not necessarily represent the official views of the Centers of

526 Disease Control and Prevention or the Department of Health and Human Services.

527 Consent for publication

528 Not applicable

529 Competing interests

530 The authors declare that they have no competing interests. 


\section{References}

532 Babyak, M. A. 2004. What you see may not be what you get: A brief, nontechnical

533 introduction to overfitting in regression-type models. Psychosom. Med. 66:

$534 \quad 411-421$.

535 Bendel, R. B., and A. A. Afifi. 1977. Comparison of stopping rules in forward

536 "stepwise" regression. J. Am. Stat. Assoc. 72: 46-53.

537 Bowden, S. E., K. Magori, and J. M. Drake. 2011. Regional differences in the

$538 \quad$ association between land cover and West Nile virus disease incidence in

539 humans in the United States. Am. J. Trop. Med. Hyg. 84: 234-238.

540 Bowen, R. A., and N. M. Nemeth. 2007. Experimental infections with West Nile $541 \quad$ virus. Curr. Opin. Infect. Dis.

542 Bursac, Z., C. H. Gauss, D. K. Williams, and D. W. Hosmer. 2008. Purposeful

543 selection of variables in logistic regression. Source Code Biol. Med. 3: 1-8.

544 CDC. 2013. West Nile Virus in the United States: Guidelines for Surveillance,

545 Prevention, and Control. Appendix 2: Calculation and Application of a Vector

546 Index (VI) Reflecting the Number of WN Virus Infected Mosquitoes in a

$547 \quad$ Population. 4th Revision.

548 CDC. 2015. National Notifiable Disease Surveillance System (NNDSS): Arboviral

549 Diseases, Neuroinvasive and Non-neuroinvasive 2015 Case Definition.

550 CDC. 2018. West Nile virus Surveillance Resources: ArboNET. 
551 CDC. 2019. National Notifiable Diseases Surveillance Systems (NNDSS): MMWR $552 \quad$ Week Fact Sheet.

553 CDC. 2020. National arboviral surveillance system (ArboNET), Arboviral Diseases

$554 \quad$ Branch, Centers for Disease Control and Prevention.

555 Centers for Disease Control and Prevention (CDC). 2010. Morbidity and

556 Mortality Weekly Report Surveillance for Human West Nile Virus Disease -

557 United States , 1999 - 2008. MMWR Wkly. Rep. 59: 1999-2008.

558 County, C. 2019. Cook County Government Open Data. Cook Cty. Data Cat.

559 Environmental Systems Research Insititute. 2011. ArcGIS Desktop. Version

$560 \quad$ 10.5.1 Redlands, CA.

561 Falchi, F., Cinzano, P., Duriscoe, D., Kyba, C. C. M., Elvidge, C. D., Baugh, K., 562 Portnov, B., Rybnikova, N. A., Furgoni, R. 2016a. The new world atlas of 563 artificial night sky brightness. Sci. Adv.

564 Falchi, F., Cinzano, P., Duriscoe, D., Kyba, C. C. M., Elvidge, C. D., Baugh, K., 565 Portnov, B., Rybnikova, N. A., Furgoni, R. 2016b. Supplement to the New 566 World Atlas of Artificial Night Sky Brightness. GFZ Data Serv.

567 Giordano, B. V., S. Kaur, and F. F. Hunter. 2017. West Nile virus in Ontario,

568 Canada: A twelve-year analysis of human case prevalence, mosquito

569 surveillance, and climate data. PLoS One. 12: 1-15.

570 Goddard, L. B., A. E. Roth, W. K. Reisen, and T. W. Scott. 2002. Vector competence 

of California mosquitoes for West Nile virus. Emerg. Infect. Dis. 8: 1385-1391.

572 Greenland, S., and R. M. Mickey. 1989. The impact of confounder selection criteria 573 on effect estimation. Am. J. Epidemiol. 130: 1066.

574 Hadfield, J., A. F. Brito, D. M. Swetnam, C. B. F. Vogels, R. E. Tokarz, K. G.

575 Andersen, R. C. Smith, T. Bedford, and N. D. Grubaugh. 2019. Twenty years

576 of West Nile virus spread and evolution in the Americas visualized by

$577 \quad$ Nextstrain. PLoS Pathog. 15: 1-18.

578 Hahn, M. B., A. J. Monaghan, M. H. Hayden, R. J. Eisen, M. J. Delorey, N. P. Lindsey,

579 R. S. Nasci, and M. Fischer. 2015. Meteorological conditions associated with

580 increased incidence of west nile virus disease in the United States, 2004-2012.

$581 \quad$ Am. J. Trop. Med. Hyg. 92: 1013-1022.

582 Hamer, G. L., U. D. Kitron, T. L. Goldberg, J. D. Brawn, S. R. Loss, M. O. Ruiz, D. B.

583 Hayes, and E. D. Walker. 2009. Host selection by Culex pipiens mosquitoes

584 and west nile virus amplification. Am. J. Trop. Med. Hyg. 80: 268-278.

585 Hawkins, D. M. 2004. The Problem of Overfitting. J. Chem. Inf. Comput. Sci. 44: 1-12.

586 Karki, S., Brown, W. M., Uelmen, J. A., Ruiz, M. O., Smith, R. L. 2019. The drivers

587 of West Nile virus human illness: fine scale dynamic effects of weather,

588 mosquito infection, social, and biological conditions. bioRxiv.

589 Kilpatrick, A. M., L. D. Kramer, M. J. Jones, P. P. Marra, and P. Daszak. 2006.

590 West Nile virus epidemics in North America are driven by shifts in mosquito

591 feeding behavior. PLoS Biol. 4: 606-610. 
592 Kilpatrick, A. M., and W. J. Pape. 2013. Predicting human west nile virus infections

593 with mosquito surveillance data. Am. J. Epidemiol. 178: 829-835.

594 Lever, J., M. Krzywinski, and N. Altman. 2016. Points of Significance: Model

595 selection and overfitting. Nat. Methods. 13: 703-704.

596 Manore, C. A., J. K. Davis, R. C. Christofferson, D. M. Wesson, J. M. Hyman, and C.

597 N. Mores. 2014. Towards an Early Warning System for Forecasting Human

598 West Nile Virus Incidence. PLoS Curr. 1-21.

599 Nelson, C. A., S. Saha, K. J. Kugeler, M. J. Delorey, M. B. Shankar, A. F. Hinckley,

600 and P. S. Mead. 2015. Incidence of clinician-diagnosed lyme disease, United

601 States, 2005-2010. Emerg. Infect. Dis. 21: 1625-1631.

602 Oregon State University. 2019. PRISM Climate Group.

603 (http://prism.oregonstate.edu).

604 Petersen, L. R., A. C. Brault, and R. S. Nasci. 2013. West Nile virus: Review of the

605 literature. JAMA - J. Am. Med. Assoc. 310: 308-315.

606 Petersen, L. R., P. J. Carson, B. J. Biggerstaff, B. Custer, S. M. Borchardt, and M. P.

607 Busch. 2013. Estimated cumulative incidence of West Nile virus infection in US

608 adults, 1999-2010. Epidemiol. Infect. 141: 591-595.

609 Read, N. R., J. R. Rooker, and J. P. Gathman. 1994. Public perception of mosquito

610 annoyance measured by a survey and simultaneous mosquito sampling. J. Am.

611 Mosq. Control Assoc. 10: 79-87. 
612 Roiz, D., S. Ruiz, R. Soriguer, and J. Figuerola. 2014. Climatic effects on mosquito

613 abundance in Mediterranean wetlands. Parasites and Vectors. 7: 1-13.

614 Rosà, R., G. Marini, L. Bolzoni, M. Neteler, M. Metz, L. Delucchi, E. A. Chadwick, L.

615 Balbo, A. Mosca, M. Giacobini, L. Bertolotti, and A. Rizzoli. 2014. Early

616 warning of West Nile virus mosquito vector: Climate and land use models

617 successfully explain phenology and abundance of Culex pipiens mosquitoes in

618 north-western Italy. Parasites and Vectors. 7: 1-12.

619 Rosenberg, R., N. P. Lindsey, M. Fischer, C. J. Gregory, A. F. Hinckley, P. S. Mead,

620 G. Paz-Bailey, S. H. Waterman, N. A. Drexler, G. J. Kersh, H. Hooks, S. K.

621 Partridge, S. N. Visser, C. B. Beard, and L. R. Petersen. 2018. Vital signs:

622 Trends in reported vectorborne disease cases - United States and Territories, 623 2004-2016. Morb. Mortal. Wkly. Rep. 67: 496-501.

624 Ruiz, M. O., C. Tedesco, T. J. McTighe, C. Austin, and K. Uriel. 2004.

625 Environmental and social determinants of human risk during a West Nile virus 626 outbreak in the greater Chicago area, 2002. Int. J. Health Geogr. 3.

627 Russell, C., and F. F. Hunter. 2012. Culex pipiens (Culicidae) is attracted to humans

628 in southern Ontario, but will it serve as a bridge vector of West Nile virus? Can.

629 Entomol.

630 Schwarz, G. 1978. Estimating the Dimension of a Model. Ann. Stat. 6: 461-464.

631 Sejvar, J. J. 2003. West Nile virus: An historical overview. Ochsner J. 5: 6-10.

632 Smithburn, K. C., T. P. Hughes, A. W. Burke, and J. H. Paul. 1940. A Neurotropic 
633 Virus Isolated from the Blood of a Native of Uganda 1. Am. J. Trop. Med. Hyg. s1$63420: 471-492$.

635 USDA. 2018. National Agriculture Imagery Program (NAIP) Imagery.

636 (https://catalog.data.gov/dataset/national-geospatial-data-asset-ngda-naip637 imagery).

638 USGS. 2011. National Geospatial Data Asset (NGDA) Land Use Land Cover.

639 USGS. 2019. EarthExplorer. (https://earthexplorer.usgs.gov/).

640 Waterman, S. H., H. S. Margolis, and J. J. Sejvar. 2015. Surveillance for dengue and 641 dengue-associated neurologic syndromes in the United States. Am. J. Trop. Med. $642 \quad$ Hyg. 92: 996-998.

643 Wimberly, M. C., A. Lamsal, P. Giacomo, and T. W. Chuang. 2014. Regional 644 variation of climatic influences on West Nile virus outbreaks in the United

645 States. Am. J. Trop. Med. Hyg. 91: 677-684.

646 
Table 1. List of covariates used previously in Cook/DuPage Counties WNV model and those newly acquired variables used in newly revised 55 hexagon UFS model.

\begin{tabular}{|c|c|c|c|c|c|}
\hline \multicolumn{4}{|c|}{ Covariate Information } & \multirow{2}{*}{$\begin{array}{c}\text { Cook/DuPage } \\
\text { Model }\end{array}$} & \multirow{2}{*}{$\begin{array}{c}\text { Ultra-fine-scal } \\
\text { Model }\end{array}$} \\
\hline Des & tion & Description & Notation & & \\
\hline \multirow{18}{*}{ Environmental } & & Proportion of developed open space & dospct & $\mathrm{X}$ & $\mathrm{X}$ \\
\hline & & Proportion of developed low intensity & dlipct & $\mathrm{X}$ & $\mathrm{X}$ \\
\hline & & Proportion of developed medium intensity & dmipct & $\mathrm{X}$ & $\mathrm{X}$ \\
\hline & & Proportion of developed high intensity & dhipct & $\mathrm{x}$ & $\mathrm{x}$ \\
\hline & & Proportion of deciduous forests & dfpct & $\mathrm{x}$ & $\mathrm{X}$ \\
\hline & & Proportion of evergreen forests & efpct & $\mathrm{x}$ & $\mathrm{X}$ \\
\hline & & Proportion of mixed forests & mfpct & $\mathrm{X}$ & $\mathrm{x}$ \\
\hline & & Proportion of barren land & blpct & $\mathrm{X}$ & $\mathrm{X}$ \\
\hline & & Proportion of shrubs & shrubspct & $\mathrm{x}$ & $\mathrm{x}$ \\
\hline & Land Cover & Proportion of grassland & glandpct & $\mathrm{x}$ & $\mathrm{x}$ \\
\hline & & Proportion of pasture & pasturepct & $\mathrm{X}$ & $\mathrm{X}$ \\
\hline & & Proportion of cultivated land & clpct & $\mathrm{X}$ & $\mathrm{x}$ \\
\hline & & Proportion of woody wetlands & wwpet & $\mathrm{x}$ & $\mathrm{X}$ \\
\hline & & Proportion of herbaceous wetlands & hwpct & $\mathrm{x}$ & $\mathrm{x}$ \\
\hline & & Proportion of total forest & ftotpct & & $\mathrm{X}$ \\
\hline & & Proportion of total wetlands & wtotpct & & $\mathrm{X}$ \\
\hline & & Proportion of open water & owpct & $\mathrm{X}$ & $\mathrm{X}$ \\
\hline & & Normalized Difference Vegetation Index & NDVI & & $\mathrm{x}$ \\
\hline & & MIR one week before & mirlag1 & $\mathrm{X}$ & $\mathrm{X}$ \\
\hline & & MIR two weeks before & mirlag2 & $\mathrm{X}$ & $\mathrm{X}$ \\
\hline & & MIR three weeks before & mirlag3 & $\mathrm{x}$ & $\mathrm{X}$ \\
\hline & & MIR four weeks before & mirlag4 & $\mathrm{x}$ & $\mathrm{x}$ \\
\hline & Minimum & Average MIR current week & MIRmean & & $\mathrm{X}$ \\
\hline & $\begin{array}{l}\text { Minımum } \\
\text { Infection Rate }\end{array}$ & Difference in weekly average MIR from 12 -year average & MIRdiff & & $\mathrm{x}$ \\
\hline & (MIR) & Vector Index current week & Vector Index & & $\mathrm{X}$ \\
\hline & & Vector Index one week before & VIlag1 & & $\mathrm{X}$ \\
\hline Biological & ------------- & Vector Index two weeks before & VIlag2 & & $\mathrm{x}$ \\
\hline & & Vector Index three weeks before & VIlag3 & & $\mathrm{X}$ \\
\hline & Mosquito & Vector Index four weeks before & VIlag4 & & $\mathrm{X}$ \\
\hline & Abundance & Light and gravid trap collection mean current week & Trap_Mean & & $\mathrm{X}$ \\
\hline & & Light and gravid trap collection mean one week before & Trap_Meanlag1 & & $\mathrm{X}$ \\
\hline & & Light and gravid trap collection mean two weeks before & Trap_Meanlag2 & & $\mathrm{X}$ \\
\hline & & Light and gravid trap collection mean three weeks before & Trap_Meanlag3 & & $\mathrm{X}$ \\
\hline & & Light and gravid trap collection mean four weeks before & Trap Meanlag4 & & $\mathrm{x}$ \\
\hline & Mosquito Biting & Mosquitoes per visit & mosquitoes per visit & & $\mathrm{X}$ \\
\hline & Rates (HLC) & Culex spp. per visit & Cx per visit & & $\mathrm{X}$ \\
\hline & & Average temperature current week & tempc & & $\mathrm{X}$ \\
\hline & & Average temperature of one week before & templag1 1 & $\mathrm{X}$ & $\mathrm{X}$ \\
\hline & Temperature & Average temperature of two weeks before & templag2 2 & $\mathrm{X}$ & $\mathrm{X}$ \\
\hline & & Average temperature of three weeks before & templag3 & $\mathrm{X}$ & $\mathrm{X}$ \\
\hline & & Average temperature of four weeks before & templag4 4 & $\mathrm{X}$ & $\mathrm{X}$ \\
\hline Weather & & Mean January temperature & Jantemp & $\bar{x}$ & $\mathrm{X}$ \\
\hline & & Average precipitation current week & preci & & $\mathrm{X}$ \\
\hline & Precinitation & Average precipitation of one week before & precilag1 & $\mathrm{X}$ & $\mathrm{X}$ \\
\hline & Precipitation & Average precipitation of two weeks before & precilag2 & $\mathrm{X}$ & $\mathrm{X}$ \\
\hline & & Average precipitation of three weeks before & precilag3 & $\mathrm{X}$ & $\mathrm{X}$ \\
\hline & & Average precipitation of four weeks before & precilag4 & $\mathrm{x}$ & $\mathrm{x}$ \\
\hline & & Percentage of White population & whitepct & $\mathrm{X}$ & $\mathrm{X}$ \\
\hline & & Percentage of African American population & blackpct & $\mathrm{X}$ & $\mathrm{X}$ \\
\hline & & Percentage of Asian population & asianpct & $\mathrm{x}$ & $\mathrm{X}$ \\
\hline & & Percentage of Hispanic population & hispanicpet & $\mathrm{x}$ & $\mathrm{X}$ \\
\hline & 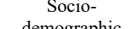 & Median household income & Income & $\mathrm{x}$ & $\mathrm{X}$ \\
\hline & & Percentage of housing constructed before WWII & hpctpreww & $\mathrm{x}$ & $\mathrm{x}$ \\
\hline & & Percentage of housing constructed post WWII (1945-1969) & hpctpostww & $\mathrm{X}$ & $\mathrm{X}$ \\
\hline & & Percentage of housing constructed from 1970-1989 & hpct7089 & $\mathrm{x}$ & $\mathrm{x}$ \\
\hline & & Percentage of housing constructed in 1990 or later & hpctpost90 & $\mathrm{X}$ & $\mathrm{x}$ \\
\hline & & Catch basin density & $\mathrm{CB}$ & & $\mathrm{X}$ \\
\hline & & Total area of building structures & bldg.._footprint_area_total & & $\mathrm{X}$ \\
\hline & & Average area of building structures & bldg._footprint_area_avg & & $\mathrm{x}$ \\
\hline & & Total perimeter of building structures & Building_Footprint_peri_total & & $\mathrm{X}$ \\
\hline & & Average perimeter of building structures & Building_Footprint_peri_avg & & $\mathrm{X}$ \\
\hline & & Total area of residential lot & Residential_lot_area total & & $\mathrm{X}$ \\
\hline & & Average area of residential lot & Residential_lot_area_avg & & $\mathrm{X}$ \\
\hline & & Total perimeter of residential lot & Residential_lot_peri_total & & $\mathrm{x}$ \\
\hline & Land change \& & Average perimeter of residential lot & Residential_lot_peri_avg & & $\mathrm{X}$ \\
\hline & $\begin{array}{l}\text { Land change \& } \\
\text { manipulation }\end{array}$ & Ratio of total building area by total lot area & total bldg. area/total lot area & & $\mathrm{x}$ \\
\hline Anthropogenic & & Ratio of average building area by average lot area & avg_bldg._area/avg_lot_area & & $\mathrm{X}$ \\
\hline & & Ratio of total building perimeter by total lot area & total_bldg._peri/total_lot_area & & $\mathrm{X}$ \\
\hline & & Ratio of average building perimeter by average lot area & avg_bldg.peri/avg_lot_area & & $\mathrm{X}$ \\
\hline & & Number of buildings & buildings & & $\mathrm{X}$ \\
\hline & & Building density per mi ${ }^{2}$ & bldg. density & & $\mathrm{X}$ \\
\hline & ------------ & Number of residents per building & persons_per_bldg. & & $\mathrm{x}$ \\
\hline & Human & & & & \\
\hline & & Total human population & totpop & $\mathrm{x}$ & $\mathrm{X}$ \\
\hline & & Mean light pollution & lightpol & & $\mathrm{X}$ \\
\hline & & Senior Citizen Observations per visit & Senior_obs per visit & & $\mathrm{X}$ \\
\hline & & Adults Observations per visist & Adults_obs per visit & & $\mathrm{X}$ \\
\hline & Activity & Children Observations per visit & Child_obs per visit & & $\mathrm{X}$ \\
\hline & Observations & Male Observations per visit & Male_obs per visit & & $\mathrm{X}$ \\
\hline & & Female Observations per visit & Female_obs per visit & & $\mathrm{X}$ \\
\hline & & Total Observations per visit & Total_obs per visit & & $\mathrm{X}$ \\
\hline & & Year & $\mathrm{yr}$ & $\mathrm{X}$ & $\mathrm{X}$ \\
\hline & & Hexagon Designation & hexid & $\mathrm{X}$ & $\mathrm{X}$ \\
\hline
\end{tabular}


648Table 2. Description of selected hexagons ( $\mathrm{n}=55)$ by residual categorization (PR1, PR0, NR1, LR1, LR0) within the Northwest Mosquito Abatement District (NWMAD). Descriptions of residual categorizations are as follows: PR = positive residual (underprediction, residuals $\geq 1.0$ ), $\mathrm{NR}=$ negative residual (great overprediction, residuals $\leq-1.0$ ), $\mathrm{LR}=$ low residuals (prediction close to actual, residuals $-1.0<\mathrm{X}<$ 1.0). Values following the residual categorizations designated as: $1=$ at least one human WNV case between 2005-2016; $0=$ no human WNV cases between 2005-2016.

HexID
\begin{tabular}{|c|c|c|c|c|}
\hline $\mathbf{4 3 4 9}$ & Cases & \multicolumn{2}{c}{ Residual } & \multicolumn{2}{c|}{ Category } & $\begin{array}{c}\text { Field } \\
\text { Season }\end{array}$ \\
\hline $\mathbf{4 8 0 6}$ & 0 & -1.001 & NRO & 1 \\
\hline $\mathbf{4 2 4 1}$ & 0 & -1 & LRO & 1 \\
\hline $\mathbf{4 8 5 4}$ & 0 & -1 & LR0 & 1 \\
\hline $\mathbf{5 2 5 0}$ & 0 & -1 & LR0 & 1 \\
\hline $\mathbf{4 2 5 0}$ & 1 & -0.271 & LR1 & 1 \\
\hline $\mathbf{4 4 7 1}$ & 2 & 0.877 & PR1 & 1 \\
\hline $\mathbf{4 1 8 3}$ & 2 & 0.902 & PR1 & 1 \\
\hline $\mathbf{4 9 8 4}$ & 1 & 0.912 & PR1 & 1 \\
\hline $\mathbf{5 1 8 8}$ & 0 & 1.134 & PRO & 1 \\
\hline $\mathbf{4 5 9 7}$ & 1 & 1.531 & PR1 & 1 \\
\hline
\end{tabular}

\begin{tabular}{|c|c|c|c|c|}
\hline HexID & Cases & Residual & Category & $\begin{array}{c}\text { Field } \\
\text { Season }\end{array}$ \\
\hline 4014 & 0 & -1.001 & NRO & Both \\
\hline 4082 & 0 & -1.001 & NRO & Both \\
\hline 4217 & 0 & -1.001 & NRO & Both \\
\hline 4415 & 0 & -1.001 & NRO & Both \\
\hline 4467 & 0 & -1 & LRO & Both \\
\hline 5199 & 0 & -1 & LRO & Both \\
\hline 5286 & 0 & -1 & LRO & Both \\
\hline 4313 & 3 & 0.033 & LR1 & Both \\
\hline 5235 & 1 & 0.055 & LR1 & Both \\
\hline 4609 & 2 & 0.399 & LR1 & Both \\
\hline 4637 & 1 & 1.027 & PR1 & Both \\
\hline 4332 & 1 & 1.279 & PR1 & Both \\
\hline 4335 & 1 & 1.767 & PR1 & Both \\
\hline 4676 & 1 & 1.838 & PR1 & Both \\
\hline 4449 & 3 & 1.841 & PR1 & Both \\
\hline 5239 & 0 & 2.198 & PRO & Both \\
\hline 4743 & 2 & 4.881 & PR1 & Both \\
\hline 5181 & 1 & 17.057 & PR1 & Both \\
\hline 4617 & 0 & 18.013 & PRO & Both \\
\hline
\end{tabular}

\begin{tabular}{|c|c|c|c|c|}
\hline HexID & Cases & Residual & Category & $\begin{array}{c}\text { Field } \\
\text { Season }\end{array}$ \\
\hline 4242 & 0 & -1.001 & NRO & 2 \\
\hline 4614 & 0 & -1.001 & NRO & 2 \\
\hline 4181 & 0 & -1 & NRO & 2 \\
\hline 4381 & 0 & -1 & NRO & 2 \\
\hline 4382 & 0 & -1 & NRO & 2 \\
\hline 4578 & 0 & -1 & NRO & 2 \\
\hline 4923 & 0 & -1 & NRO & 2 \\
\hline 5185 & 0 & -1 & NRO & 2 \\
\hline 5262 & 0 & -1 & NRO & 2 \\
\hline 5234 & 1 & -0.338 & LR1 & 2 \\
\hline 4070 & 1 & -0.32 & LR1 & 2 \\
\hline 4952 & 1 & -0.193 & LR1 & 2 \\
\hline 4073 & 1 & -0.038 & LR1 & 2 \\
\hline 4678 & 1 & -0.014 & LR1 & 2 \\
\hline 4135 & 1 & -0.002 & LR1 & 2 \\
\hline 4104 & 1 & 0 & LR1 & 2 \\
\hline 4334 & 1 & 0.024 & LR1 & 2 \\
\hline 4243 & 2 & 0.071 & LR1 & 2 \\
\hline 5126 & 1 & 0.11 & LR1 & 2 \\
\hline 4065 & 1 & 0.181 & LR1 & 2 \\
\hline 5265 & 1 & 0.221 & LR1 & 2 \\
\hline 4098 & 1 & 5.557 & PR1 & 2 \\
\hline 4636 & 1 & 6.481 & PR1 & 2 \\
\hline 4346 & 1 & 6.967 & PR1 & 2 \\
\hline 4310 & 1 & 17.856 & PR1 & 2 \\
\hline
\end{tabular}




\begin{tabular}{|c|c|c|c|c|c|c|c|}
\hline A. $\begin{array}{c}\text { Regression } \\
\text { Method }^{\mathbf{a}}\end{array}$ & $\begin{array}{c}\text { Model } \\
\text { Environment }\end{array}$ & Included Covariates & df & p-value & ROC $^{b}$ & BIC & $\Delta \mathrm{BIC}$ \\
\hline \multirow{4}{*}{ 1. Logistic } & $\begin{array}{l}\text { 1. MIR \& } \\
\text { Mosquito } \\
\text { Abundance } \\
\left(\mathrm{E}_{1} \mathrm{C}_{2} \mathrm{O}_{1}\right)\end{array}$ & 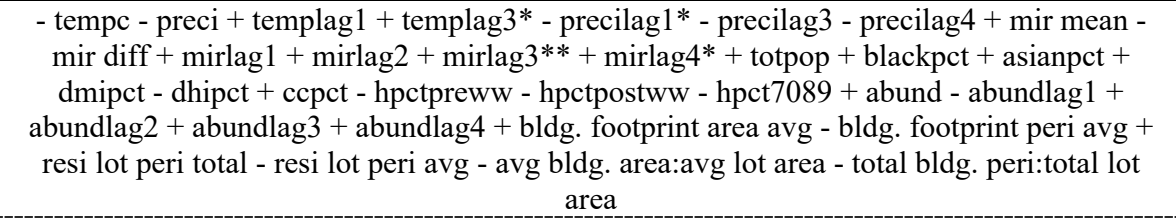 & 34 & $<0.0001$ & 0.89 & 768.7 & 128.3 \\
\hline & $\begin{array}{l}\text { 2. Vector } \\
\text { Index } \\
\left(\mathrm{E}_{2} \mathrm{C}_{2} \mathrm{O}_{1}\right)\end{array}$ & $\begin{array}{l}- \text { tempc - preci + templag1 + templag2 + templag3** - precilag1* - precilag4 + totpop + } \\
\text { blackpct }+ \text { asianpct + hispanicpct }- \text { Income + dospct }- \text { dmipct - hpctpreww - hpct7089 + CB } \\
\text { + avg bldg. area:avg lot area*** + VI - VIlag1 + VIlag2 + VIlag3 } 3 * \text { VIlag } 4\end{array}$ & 23 & $<0.0001$ & 0.86 & 661.1 & 20.7 \\
\hline & $\begin{array}{l}\text { 3. Best-Fit } \\
\left(\mathrm{E}_{3} \mathrm{C}_{2} \mathrm{O}_{1}\right)\end{array}$ & 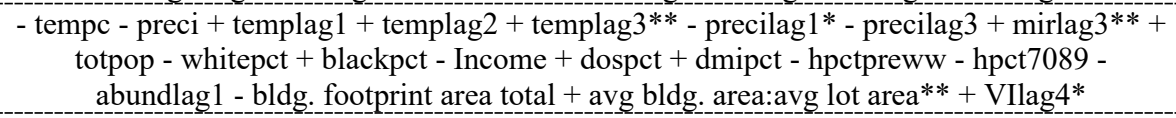 & 21 & $<0.0001$ & 0.86 & 640.4 & 0 \\
\hline & $\begin{array}{l}\text { 4. Global } \\
\left(\mathrm{E}_{4} \mathrm{C}_{2} \mathrm{O}_{1}\right)\end{array}$ & 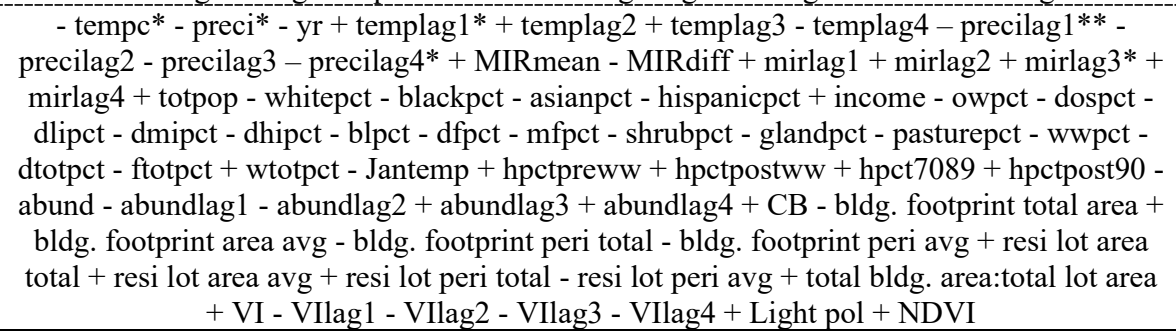 & 65 & 0.0009 & 0.97 & 833.5 & 193.1 \\
\hline \multirow{4}{*}{ 2. Linear } & $\begin{array}{l}\text { 1. MIR \& } \\
\text { Mosquito } \\
\text { Abundance } \\
\left(\mathrm{E}_{1} \mathrm{C}_{2} \mathrm{O}_{2}\right)\end{array}$ & $\begin{array}{l}\text { mir mean }+ \text { mir } \operatorname{diff}+\operatorname{mirlag} 1+\operatorname{mirlag} 2+\text { mirlag } 3+\text { mirlag } 4 *+\text { blpct } * *+\text { abund }- \\
\text { abundlag } 1-\text { abundlag } 2+\text { abundlag } 3+\text { abundlag } 4 *+\text { bldg. footprint area avg } * * *\end{array}$ & 13 & $<0.0001$ & \multirow{4}{*}{ N/A } & -182037 & 3358 \\
\hline & $\begin{array}{l}\text { 2. Vector } \\
\text { Index } \\
\left(\mathrm{E}_{2} \mathrm{C}_{2} \mathrm{O}_{2}\right)\end{array}$ & $\begin{array}{l}\text { bldg. footprint area avg***+ avg bldg. area:avg lot area***+ VI - VIlag1 + VIlag2 + } \\
\text { VIlag3*+ VIlag4*** }\end{array}$ & 7 & $<0.0001$ & & -185373 & 22 \\
\hline & $\begin{array}{l}\text { 3. Best-Fit } \\
\left(\mathrm{E}_{3} \mathrm{C}_{2} \mathrm{O}_{2}\right)\end{array}$ & - mirlag $4+$ bldg. footprint area avg $* * *+$ avg bldg. area:avg lot area** + VIlag $4 * * *$ & 4 & $<0.0001$ & & -185395 & 0 \\
\hline & $\begin{array}{l}\text { 4. Global } \\
\left(\mathrm{E}_{4} \mathrm{C}_{2} \mathrm{O}_{2}\right)\end{array}$ & 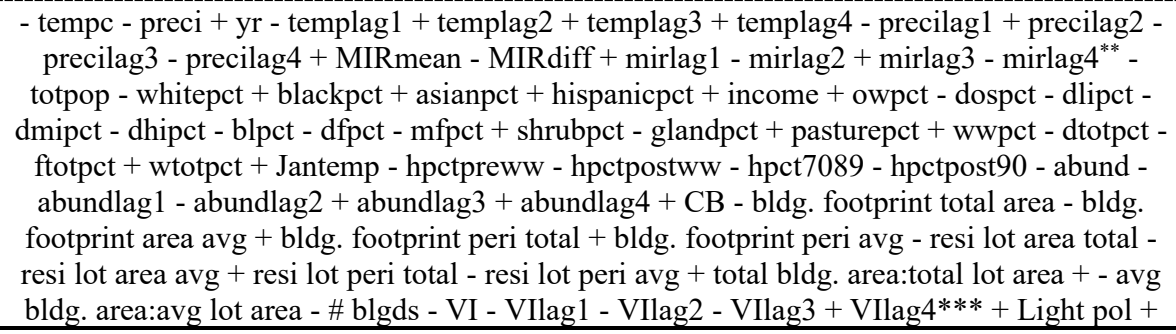 & 68 & 0.0044 & & -94558.2 & 90836.8 \\
\hline
\end{tabular}


Table 3. Model fit comparisons of the UFS hexagons, applying (A) newly acquired data (excluding HLC and human observations,

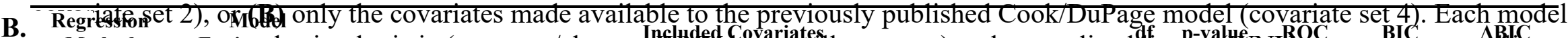

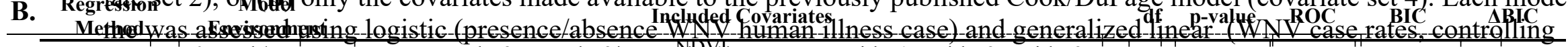

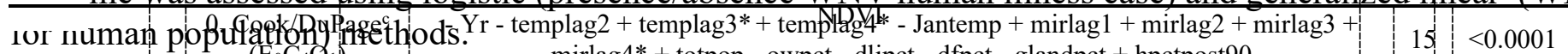

IUI IIUTa ${ }_{\left(\mathrm{E}_{0} \mathrm{C}_{4} \mathrm{O}_{1}\right)} \quad$ mirlag4* + totpop - owpct - dlipct - dfpct - glandpct + hpctpost90

1. MIR \&

dhipct - mfpct - wwpct + mirlag $1+\operatorname{mirlag} 2+\operatorname{mirlag} 3 *+\operatorname{mirlag} 4+$ templag $3+$

1. Logistic

Mosquito

Abundance

emplag $4 *$ precilag $1 *$ recilag 2 - mirmean-m

diff + abund - abundlag $1 *+$ abundlag $2+$ abundlag $3+$ abundlag 4

2. Vector Index dhipct - mfpct - wwpct + templag3* + templag4* - precilag1* - precilag2 - precilag4* + $\left(\mathrm{E}_{2} \mathrm{C}_{4} \mathrm{O}_{1}\right)$ asianpct + VIlag1 + VIlag2 + VIlag3* + VIlag4

3. Best-fit 55 hex dhipct - mfpct - wwpct + mirlag3* + mirlag4 + templag3* + templag4** - precilag $1^{*}$ $\left(\mathrm{E}_{3} \mathrm{C}_{4} \mathrm{O}_{1}\right)$

dhipct - mfpct - wwpct + mirlag $3 *+\operatorname{mirlag} 4+$ templag3* + templag
precilag2 2 - precilag4* 4 asianpct**+ totpop

632.3

56.

$12<0.0001$

0.89

580.8 


\begin{tabular}{|c|c|c|c|c|c|c|c|}
\hline & $\begin{array}{l}\text { 4. Global } \\
\left(\mathrm{E}_{4} \mathrm{C}_{4} \mathrm{O}_{1}\right)\end{array}$ & 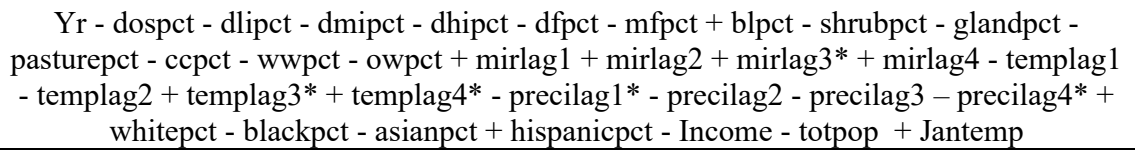 & 33 & $<0.0001$ & 0.90 & 792.0 & 215.8 \\
\hline \multirow{5}{*}{ 2. Linear } & $\begin{array}{l}\text { 0. Cook/DuPage } \\
\left(\mathrm{E}_{0} \mathrm{C}_{4} \mathrm{O}_{2}\right)\end{array}$ & $\begin{array}{l}\text { Yr - templag } 2+\text { templag } 3+\text { templag } 4+\text { Jantemp }+ \text { mirlag } 1+\text { mirlag } 2+\text { mirlag } 3 *+ \\
\text { mirlag } 4 * * \text { - totpop* - owpct* - dlipct }- \text { dfpct* - glandpct }+ \text { hpctpost90 }\end{array}$ & 15 & $<0.0001$ & \multirow{5}{*}{$N / A^{b}$} & -227354 & 90 \\
\hline & $\begin{array}{l}\text { 1. MIR \& } \\
\text { Mosquito } \\
\text { Abundance } \\
\left(\mathrm{E}_{1} \mathrm{C}_{4} \mathrm{O}_{2}\right)\end{array}$ & $\begin{array}{l}\text { Dmipct } * *+\text { blpct** }+ \text { mirlag } 1+\operatorname{mirlag} 2+\operatorname{mirlag} 3+\operatorname{mirlag} 4 *+\text { templag } 3-\text { precilag } 1- \\
\text { precilag } 4-\text { totpop* }- \text { mir mean }+ \text { mir diff - abund }- \text { abundlag } 1+\text { abundlag } 2-\text { abundlag3 } \\
+ \text { abundlag } 4 *\end{array}$ & 17 & $<0.0001$ & & -182001 & 45443 \\
\hline & $\begin{array}{l}\text { 2. Vector Index } \\
\left(\mathrm{E}_{2} \mathrm{C}_{4} \mathrm{O}_{2}\right)\end{array}$ & $\begin{array}{c}\text { dlipct }+ \text { dmipct } * * *+\text { templag3 } * \text { totpop } * *-\text { VI }- \text { VIlag1 }+ \text { VIlag2 }+ \text { VIlag3* + } \\
\text { VIlag4*** }\end{array}$ & 9 & $<0.0001$ & & -185347 & 42097 \\
\hline & $\begin{array}{l}\text { 3. Best-fit } 55 \text { hex } \\
\left(\mathrm{E}_{3} \mathrm{C}_{4} \mathrm{O}_{2}\right)\end{array}$ & $\begin{array}{l}\text { Dmipct** }+ \text { blpct** }+ \text { mirlag3** } \\
\text { totpop* }\end{array}$ & 8 & $<0.0001$ & & -227444 & 0 \\
\hline & $\begin{array}{l}\text { 4. Global } \\
\left(\mathrm{E}_{4} \mathrm{C}_{4} \mathrm{O}_{2}\right)\end{array}$ & $\begin{array}{l}\text { Yr - dospct - dlipct - dmipct - dhipct - dfpct - mfpct + blpct - shrubpct - glandpct - } \\
\text { pasturepct - ccpct - wwpct - owpct + mirlag1 + mirlag2 + mirlag3* + mirlag4* - } \\
\text { templag1 - templag2 + templag3 + templag4 - precilag1 - precilag2 - precilag3 - } \\
\text { precilag4 + whitepct - blackpct - asianpct + hispanicpct - Income - totpop* + Jantemp }\end{array}$ & 33 & $<0.0001$ & & -227199 & 245 \\
\hline
\end{tabular}

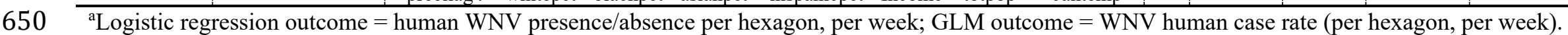

$651{ }^{b}$ ROC applies to only logistic regression.

$652{ }^{\mathrm{c}}$ As the final selected model in the Original Cook/DuPage paper (2019), this model environment was assessed only for the comparison to the

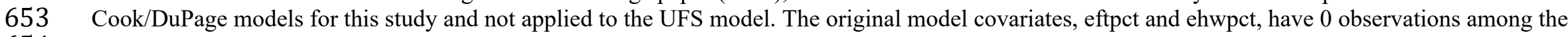

654 selected 55 hexagons and were removed. 
Table 4. Model fit comparisons of the UFS hexagons, using best-fit models with additional human landing catch and human activity observations to incorporate added human risk. Human risk covariates were added to the UFS model by (A) best-fit integration (covariate set 1) and (B) force-fitting (covariate set 3).

\begin{tabular}{|c|c|c|c|c|c|c|c|}
\hline A. $\begin{array}{c}\text { Regression } \\
\text { Method }\end{array}$ & $\begin{array}{c}\text { Model } \\
\text { Environment }\end{array}$ & Included Covariates & df & p-value & AUC & BIC & $\Delta \mathrm{BIC}$ \\
\hline \multirow{4}{*}{ 1. Logistic } & $\begin{array}{l}\text { 1.MIR \& } \\
\text { Mosquito } \\
\text { Abundance } \\
\left(\mathrm{E}_{1} \mathrm{C}_{1} \mathrm{O}_{1}\right)\end{array}$ & $\begin{array}{c}\text { - tempc - preci + templag } 1 \text { - templag } 2+\text { templag } 3 * \text { - precilag } 1 * \text { - precilag } 3 \text { - precilag } 4+ \\
\text { mirmean - mirdiff }+ \text { mirlag } 1+\text { mirlag } 2+\text { mirlag } 3 * *+\text { mirlag } 4-\text { whitepct }+ \text { blackpct }+ \text { dospct }- \\
\text { dmipct }- \text { hpctpreww }- \text { hpct } 7089+\text { abund }- \text { abundlag } 1+\text { abundlag } 2+\text { abundlag } 3+\text { abundlag } 4+ \\
\text { bldg. footprint area total - total bldg. area:total lot area }+ \text { male obs per visit }+ \text { female obs per visit } \\
+ \text { Culex per visit }\end{array}$ & 30 & $<0.0001$ & 0.87 & 742.5 & 107.9 \\
\hline & $\begin{array}{l}2 . \text { Vector } \\
\text { Index } \\
\left(\mathrm{E}_{2} \mathrm{C}_{1} \mathrm{O}_{1}\right)\end{array}$ & $\begin{array}{c}- \text { tempc - preci + templag1 + templag2 + templag3** - precilag1* - precilag4 }- \text { whitepct }+ \\
\text { blackpct }+ \text { dmipct }- \text { hpctpreww }- \text { hpctpostww }- \text { hpct7089 + male obs per visit }+ \text { female obs per } \\
\text { visit }+ \text { VI - VIlag1 + VIlag2 + VIlag } 3 *+\text { VIlag } 4\end{array}$ & 26 & $<0.0001$ & 0.86 & 692.7 & 58.1 \\
\hline & $\begin{array}{l}\text { 3. Best-Fit } \\
\left(\mathrm{E}_{3} \mathrm{C}_{1} \mathrm{O}_{1}\right)\end{array}$ & $\begin{array}{c}\text { - tempc }- \text { preci }+ \text { templag } 1+\text { templag } 2+\text { templag } 3 * * \text { precilag } 1 *-\text { precilag } 4+\text { mirlag } 3 * *+ \\
\text { blackpct }- \text { dospct }+ \text { dmipct }- \text { hpctpreww }- \text { hpct } 7089+\text { abund }+ \text { Light pol }+ \text { male obs per visit }+ \\
\text { female obs per visit }+ \text { Culex per visit + VIlag } 4\end{array}$ & 19 & $<0.0001$ & 0.84 & 634.6 & 0 \\
\hline & $\begin{array}{l}\text { 4. } \mathrm{Global}^{\mathrm{a}} \\
\left(\mathrm{E}_{4} \mathrm{C}_{1} \mathrm{O}_{1}\right)\end{array}$ & 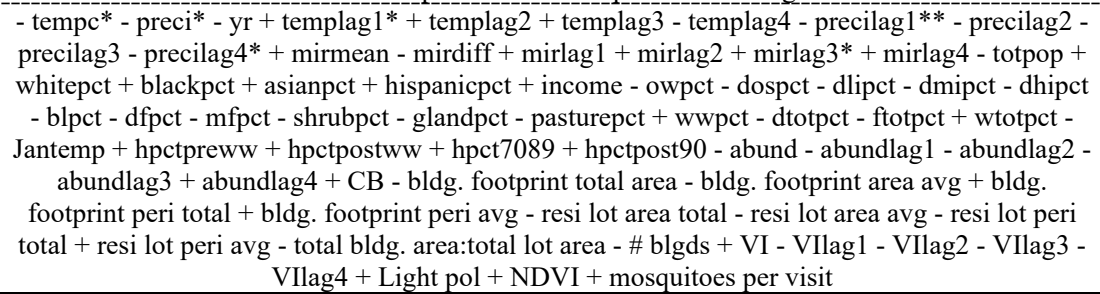 & 65 & 0.0009 & 0.97 & 772.8 & 138.2 \\
\hline \multirow{4}{*}{ 2. Linear } & $\begin{array}{l}\text { 1. MIR \& } \\
\text { Mosquito } \\
\text { Abundance } \\
\left(\mathrm{E}_{1} \mathrm{C}_{1} \mathrm{O}_{2}\right)\end{array}$ & 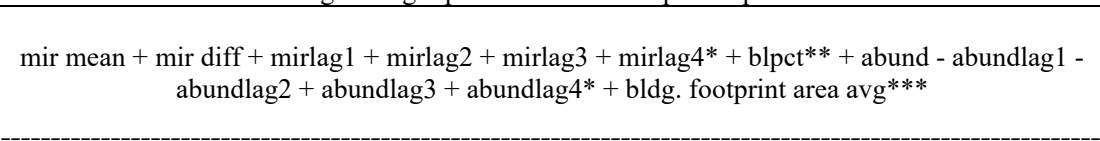 & 13 & $<0.0001$ & N/A & -182037 & 3352 \\
\hline & $\begin{array}{l}\text { 2. Vector } \\
\text { Index } \\
\left(\mathrm{E}_{2} \mathrm{C}_{1} \mathrm{O}_{2}\right)\end{array}$ & $\begin{array}{c}\text { templag } 3 *+\text { bldg. footprint area avg } * * * \text { - resi lot peri avg }+ \text { VI }- \text { VIlag1 }+ \text { VIlag2 }+ \text { VIlag } 3 *+ \\
\text { VIlag } 4 * * *\end{array}$ & 8 & $<0.0001$ & & -185362 & 27 \\
\hline & $\begin{array}{l}\text { 3. Best-Fit } \\
\left(\mathrm{E}_{3} \mathrm{C}_{1} \mathrm{O}_{2}\right)\end{array}$ & - mirlag $4+$ bldg. footprint area avg ${ }^{* * *}$ - resi lot peri avg + VIlag4*** & 4 & $<0.0001$ & & -185389 & 0 \\
\hline & $\begin{array}{l}\text { 4. } \mathrm{Global}^{\mathrm{b}} \\
\left(\mathrm{E}_{4} \mathrm{C}_{1} \mathrm{O}_{2}\right)\end{array}$ & $\begin{array}{l}\text { - tempc - preci + yr - templag } 1+\text { templag } 2+\text { templag } 3 \text { templag4 - precilag } 1+\text { precilag2 - } \\
\text { precilag3 - precilag4 + mirmean - mirdiff + mirlag1 - mirlag2 + mirlag3 - mirlag4** - totpop + } \\
\text { whitepct + blackpct + asianpct + hispanicpct + income - owpct - dospct - dlipct - dmipct - dhipct } \\
\text { - blpct - dfpct - mfpct - shrubpct - glandpct - pasturepct + wwpct - dtotpct - ftotpct + wtotpct }+ \\
\text { Jantemp - hpctpreww - hpctpostww - hpct7089 - hpctpost } 90 \text { - abund - abundlag } 1 \text { - abundlag2 - } \\
\text { abundlag3 + abundlag4 + CB - bldg. footprint total area - bldg. footprint area avg + bldg. } \\
\text { footprint peri total + bldg. footprint peri avg - resi lot area total - resi lot area avg + resi lot peri } \\
\text { total - resi lot peri avg - total bldg. area:total lot area - avg bldg. area:avg lot area - \# blgds - VI - } \\
\text { VIlag1 - VIlag2 - VIlag3 + VIlag4*** + Light pol + NDVI + senior obs per visit }\end{array}$ & 64 & 0.0022 & & -94581.4 & 90797.6 \\
\hline
\end{tabular}




\begin{tabular}{|c|c|c|c|c|c|c|c|}
\hline B. $\begin{array}{c}\text { Regression } \\
\text { Method }\end{array}$ & $\begin{array}{c}\text { Model } \\
\text { Environment }\end{array}$ & Included Covariates & df & p-value & $\mathbf{R O C}^{\mathbf{b}}$ & BIC & $\Delta \mathrm{BIC}$ \\
\hline \multirow{5}{*}{ 1. Logistic } & $\begin{array}{l}\text { 0. Cook/DuPage } \\
\left(\mathrm{E}_{0} \mathrm{C}_{3} \mathrm{O}_{1}\right)\end{array}$ & $\begin{array}{l}\text { - Yr - templag2 }+ \text { templag } 3 *+\text { templag4 } * \text { - Jantemp }+ \text { mirlag } 1+\text { mirlag } 2+\text { mirlag } 3 *+\text { mirlag } 4 *- \\
\text { totpop - owpct - dlipct - dfpct - glandpct }+ \text { hpctpost } 90-\text { senior obs per visit }- \text { adult obs per visit }+ \\
\text { child obs per visit }+ \text { male obs per visit - mosquitoes per visit }+ \text { Culex per visit }\end{array}$ & 21 & $<0.0001$ & 0.86 & 683.4 & 10.7 \\
\hline & $\begin{array}{l}\text { 1. MIR \& } \\
\text { Mosquito } \\
\text { Abundance } \\
\left(\mathrm{E}_{1} \mathrm{C}_{3} \mathrm{O}_{1}\right)\end{array}$ & 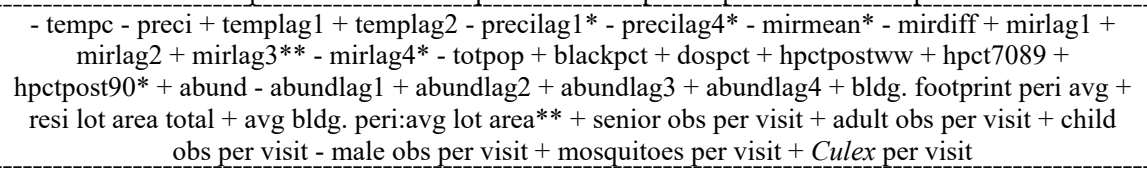 & 32 & $<0.0001$ & 0.87 & 757.7 & 61.1 \\
\hline & $\begin{array}{l}\text { 2. Vector Index } \\
\left(\mathrm{E}_{2} \mathrm{C}_{3} \mathrm{O}_{1}\right)\end{array}$ & 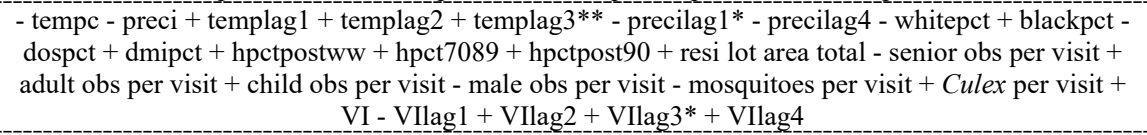 & 26 & $<0.0001$ & 0.85 & 696.6 & 23.9 \\
\hline & $\begin{array}{l}\text { 3. Best-fit } 55 \\
\text { hex } \\
\left(\mathrm{E}_{3} \mathrm{C}_{3} \mathrm{O}_{1}\right)\end{array}$ & $\begin{array}{c}- \text { tempc }- \text { preci }+ \text { templag } 1+\text { templag } 2+\text { templag } 3^{* *} \text { - precilag } 1^{*}-\text { precilag } 4-\text { whitepct }+ \text { blackpct }- \\
\text { dospct }+ \text { dmipct }+ \text { hpctpostww }+ \text { hpct } 7089+\text { resi lot area total }- \text { senior obs per visit }+ \text { adult obs per } \\
\text { visit }+ \text { child obs per visit }- \text { male obs per visit - mosquitoes per visit }+ \text { Culex per visit }+ \text { VIlag } 4+ \\
\text { mirlag } 3^{* *} \text { - abund }\end{array}$ & 23 & $<0.0001$ & 0.84 & 672.7 & 0 \\
\hline & $\begin{array}{l}\text { 4. Global } \\
\left(\mathrm{E}_{4} \mathrm{C}_{3} \mathrm{O}_{1}\right)\end{array}$ & Model Failed to Converge & N/A & N/A & N/A & N/A & N/A \\
\hline \multirow{5}{*}{ 2. Linear } & $\begin{array}{l}\text { 0. Cook/DuPage } \\
\quad\left(\mathrm{E}_{0} \mathrm{C}_{3} \mathrm{O}_{2}\right)\end{array}$ & $\begin{array}{l}\text { Yr }- \text { templag } 2+\text { templag } 3+\text { templag } 4+\text { Jantemp }+ \text { mirlag } 1+\text { mirlag } 2+\text { mirlag } 3 *+\text { mirlag } 4 * *- \\
\text { totpop* - owpct* - dlipct }- \text { dfpct* - glandpct }+ \text { hpctpost } 90 \text { - senior obs per visit }+ \text { adult obs per visit } \\
\text { + child obs per visit - male obs per visit }+ \text { mosquitoes per visit }- \text { Culex per visit }\end{array}$ & 21 & $<0.0001$ & \multirow{5}{*}{ N/A } & -227300 & 0 \\
\hline & $\begin{array}{l}\text { 1. MIR \& } \\
\text { Mosquito } \\
\text { Abundance } \\
\left(\mathrm{E}_{1} \mathrm{C}_{3} \mathrm{O}_{2}\right)\end{array}$ & $\begin{array}{l}\text { blpct** + bldg. footprint area avg*** - senior obs per visit }+ \text { adult obs per visit }+ \text { child obs per visit - } \\
\text { male obs per visit }- \text { mosquitoes per visit }+ \text { Culex per visit }+ \text { mirmean }+ \text { mirdiff }+ \text { mirlag } 1+\text { mirlag } 2 \\
+ \text { mirlag } 3+\text { mirlag } 4 *+\text { abund }- \text { abundlag } 1 \text { - abundlag } 2 \text { - abundlag } 3+\text { abundlag } 4 *\end{array}$ & 19 & $<0.0001$ & & -181982 & 45318 \\
\hline & $\begin{array}{l}\text { 2. Vector Index } \\
\left(\mathrm{E}_{2} \mathrm{C}_{3} \mathrm{O}_{2}\right)\end{array}$ & $\begin{array}{l}\text { bldg. footprint area avg*** + adult obs per visit }+ \text { child obs per visit }+ \text { female obs per visit }- \text { total } \\
\text { obs per visit }- \text { mosquitoes per visit }+ \text { Culex per visit }+ \text { VI }- \text { VIlag } 1+\text { VIlag } 2+\text { VIlag } 3 *+\text { VIlag } 4 * * *\end{array}$ & 12 & $<0.0001$ & & -185322 & 41978 \\
\hline & $\begin{array}{l}\text { 3. Best-fit } 55 \\
\text { hex } \\
\left(\mathrm{E}_{3} \mathrm{C}_{3} \mathrm{O}_{2}\right)\end{array}$ & $\begin{array}{l}\text { bldg. footprint area avg*** - senior obs per visit - adult obs per visit }+ \text { child obs per visit }+ \text { female } \\
\text { obs per visit - mosquitoes per visit }+ \text { Culex per visit + VIlag } 4 * * * \text { - mirlag } 4\end{array}$ & 9 & $<0.0001$ & & -185344 & 41956 \\
\hline & $\begin{array}{l}\text { 4. } \mathrm{Global}^{\mathrm{g}} \\
\left(\mathrm{E}_{4} \mathrm{C}_{3} \mathrm{O}_{2}\right)\end{array}$ & 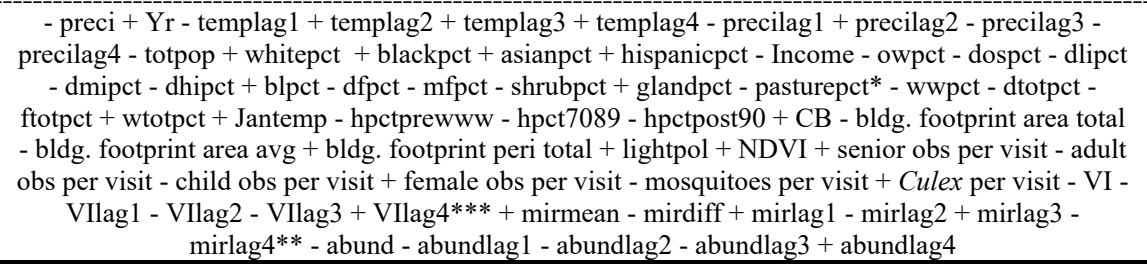 & 63 & 0.0013 & & -94601.5 & 132699 \\
\hline
\end{tabular}

658 avg bldg. peri:avg lot area, \# bldg.s, Observations per visit: senior, adult, child, male, female, total human and Culex spp. were biased and/or zeroed and 659 not assessed.

660 bobservations per minute: adult, child, male, female, total human, mosquito, and Culex spp. were biased and/or zeroed and not assessed.

661 é Observations per minute: female and total human were biased and/or zeroed and not assessed.

662 Observations per minute: male and senior were biased and/or zeroed and not assessed.

$663{ }^{\mathrm{g}}$ Observations per minute: male and total human were biased and/or zeroed and not assessed. 
Table 5. Detailed assessment of each model evaluated in this study. Overall model strength was determined by BIC value (by linear and logistic regression types), with the following characteristics denoted as follows: Cumulative Significance Total, sum of each variable score, denoted as: $\mathrm{p}<0.001=4, \mathrm{p}<0.01=3, \mathrm{p}<0.05=2$, included in model $=1$; \# of Significant Covariates $=$ summation of included covariates with $\mathrm{p}$-value $<0.05 ; \mathrm{DF}=$ degrees of freedom denoted in model; $\mathrm{BIC}$ value $=$ overall model rank $($ best model $=1$, worst model $=$ 14)/14 for each logistic and linear model group, respectively.

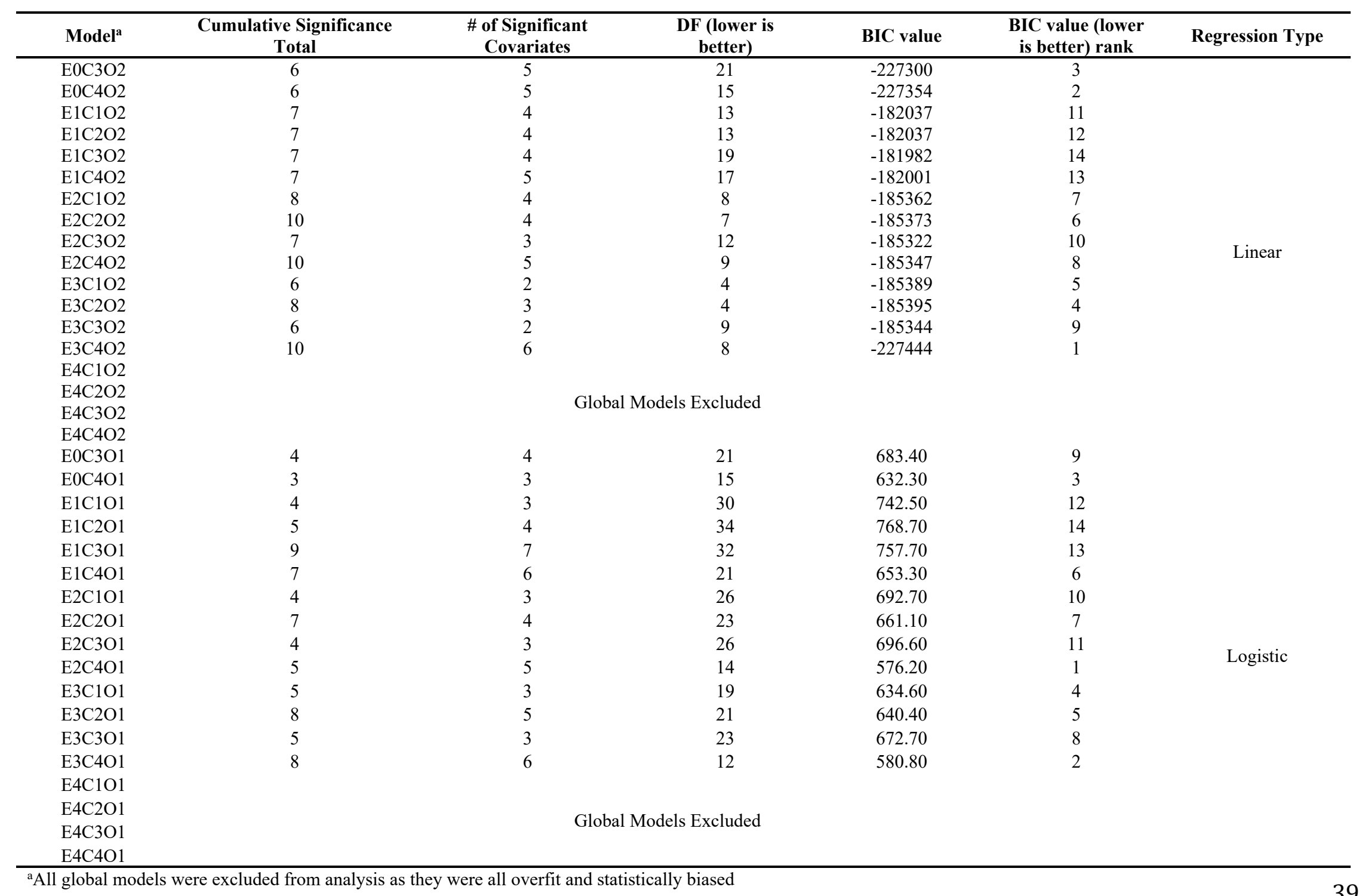




\section{Figure Captions}

666 Figure 1. The UFS study area, contained within the Northwest Mosquito Abatement District,

667 shown in relation to Cook \& DuPage Counties. Overlaid are 1-km diameter hexagons, the

668 observational units used in this study. Northwest Mosquito Abatement District comprises 1,019

669 of the total 5,345 hexagons in all of Cook \& DuPage Counties.

670 Figure 2. Location of the 55-hexagon study area within the Northwest Abatement District.

671 Hexagons are labeled by field season visited for mosquito collections and human activity

672 observations (color outline) and by total human cases from 2005-2016 (gray scale shaded

673 interior).

674 Figure 3. Mean performance of each of the 70 covariates used in the study (A). Covariates are

675 listed in alphabetic order by data availability/work load to acquire score (1-4). The contribution

676 of each covariate resulted in a net value performance for each linear and logistic model assessed

677 in the study (B). Means for each outcome $\left(\bar{x}_{\text {covariate }}=0.48 ; \bar{x}_{\text {linear }}=-193406 ; \bar{x}_{\text {logistic }}=670.9\right)$ are

678 designated by horizontal dashed lines. Details of scoring for each covariate and model are

679 provided in Tables 5 \& S1

680 Figure 4. Relationship of hexagon type $(\mathrm{LR}=$ low residual, $\mathrm{PR}=$ positive residual, $\mathrm{NR}=$ large,

681 negative residual; $0=$ no human case, $1=$ human case) by human observations per visit (A),

682 mosquitoes collected per visit (B), and a product of the two former variables, nuisance factor and

683 WNV added risk (C). Letters above each box and whisker plot designate significantly different

684 groups by hexagon type, as calculated by Tukey's HSD.

685 Figure 5. Relationship of each of the 55 UFS study hexagons (y-axis = unique identification 686 number) by nuisance mosquito factor (A) and human WNV added risk (B). Letters above each 
687 box and whisker plot designate significantly different groups by hexagon type, as calculated by 688 Tukey's HSD. 
Figures

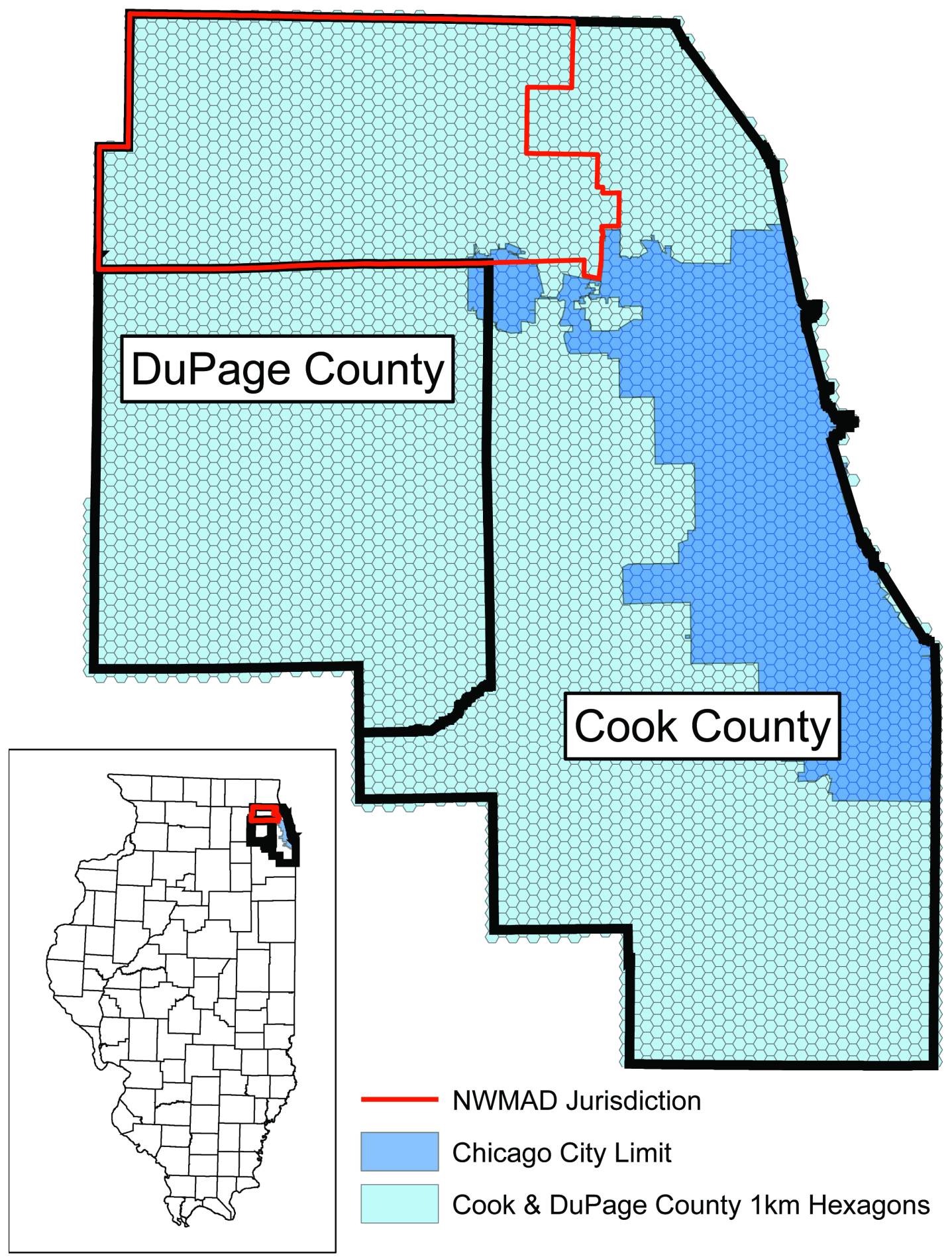

Figure 1

The UFS study area, contained within the Northwest Mosquito Abatement District, shown in relation to Cook \& DuPage Counties. Overlaid are 1-km diameter hexagons, the observational units used in this 
study. Northwest Mosquito Abatement District comprises 1,019 of the total 5,345 hexagons in all of Cook \& DuPage Counties.

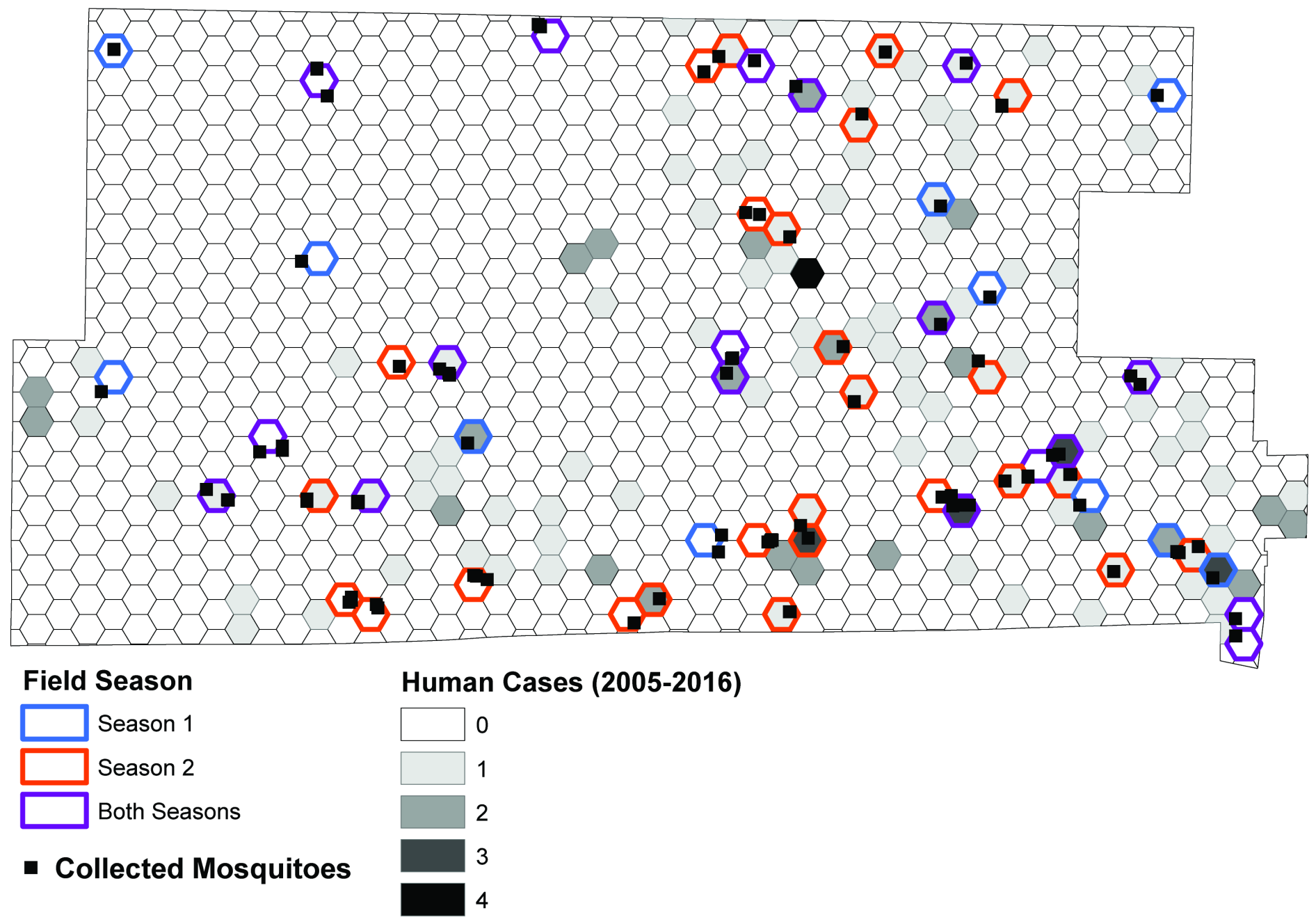

Figure 2

Location of the 55-hexagon study area within the Northwest Abatement District. Hexagons are labeled by field season visited for mosquito collections and human activity observations (color outline) and by total human cases from 2005-2016 (gray scale shaded interior). 


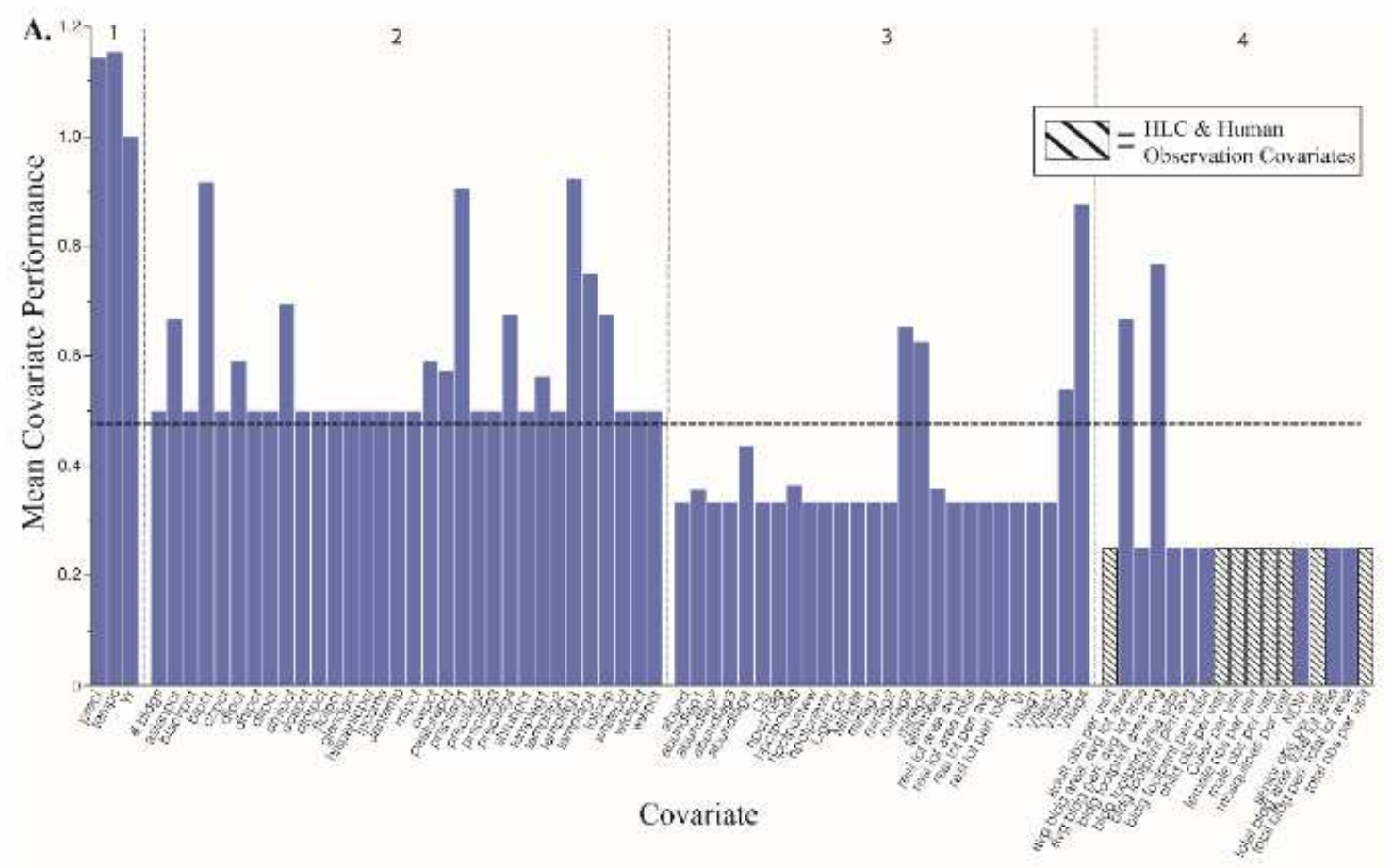

B.

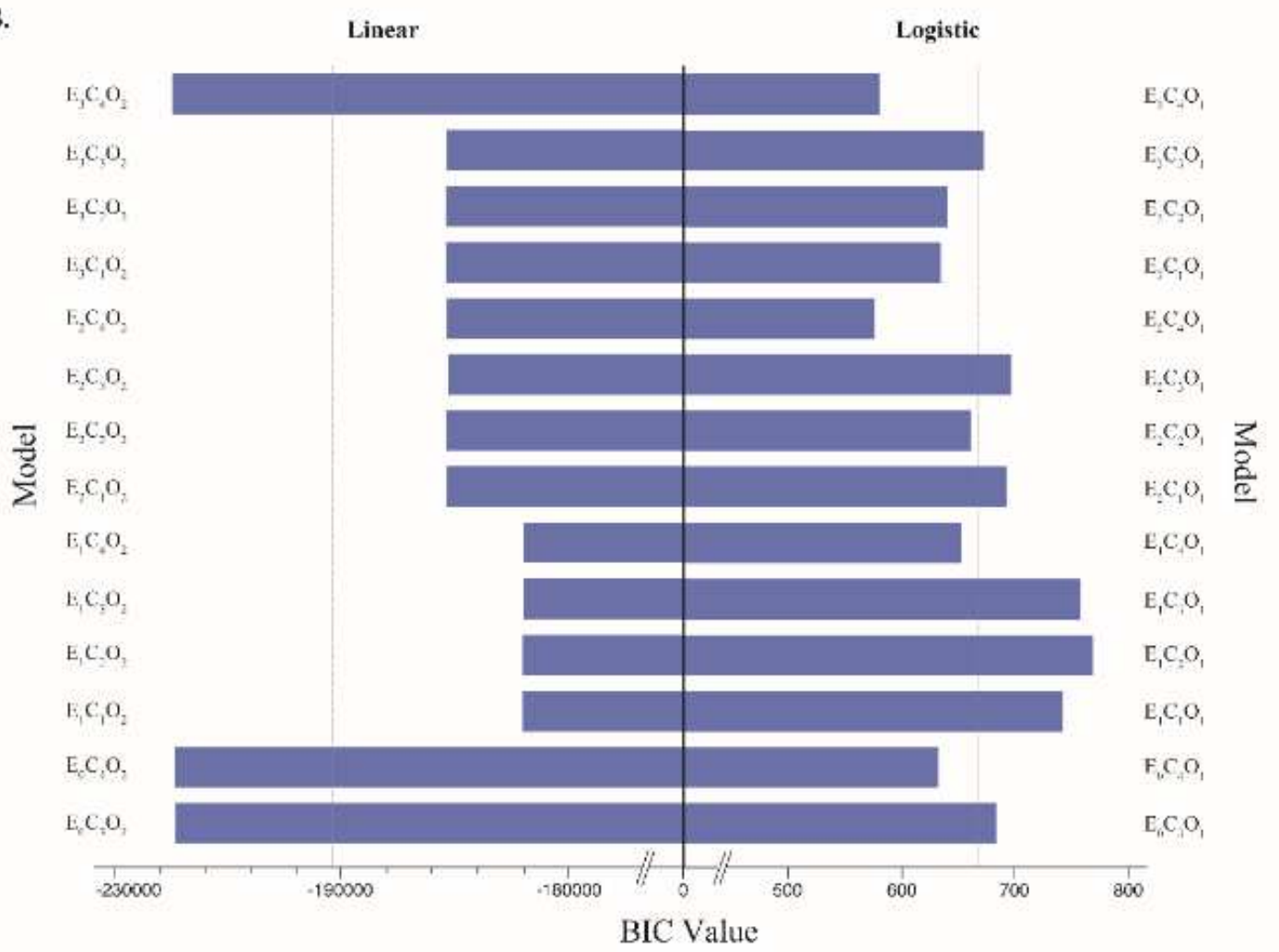

\section{Figure 3}

Mean performance of each of the 70 covariates used in the study (A). Covariates are listed in alphabetic order by data availability/work load to acquire score (1-4). The contribution of each covariate resulted in a net value performance for each linear and logistic model assessed in the study (B). Means for each outcome $(x$ \covariate $=0.48 ; x$ \linear $=-193406 ; x$ \logistic $=670.9)$ are designated by horizontal dashed lines. Details of scoring for each covariate and model are provided in Tables 5 \& S1 


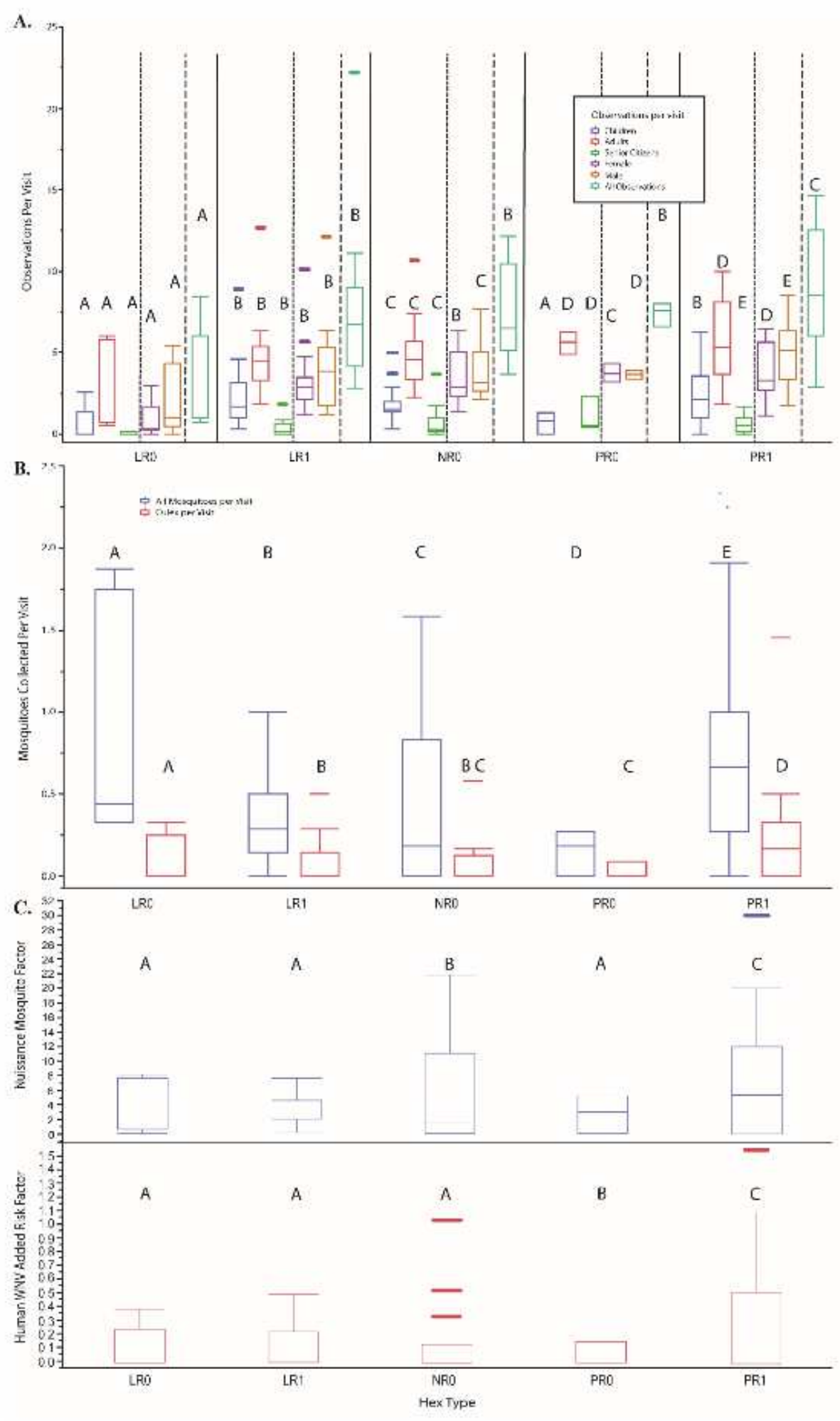

\section{Figure 4}

Relationship of hexagon type $(\mathrm{LR}=$ low residual, $\mathrm{PR}=$ positive residual, $\mathrm{NR}=$ large, negative residual; $0=$ no human case, 1 = human case) by human observations per visit (A), mosquitoes collected per visit (B), and a product of the two former variables, nuisance factor and WNV added risk (C). Letters above each box and whisker plot designate significantly different groups by hexagon type, as calculated by Tukey's HSD. 

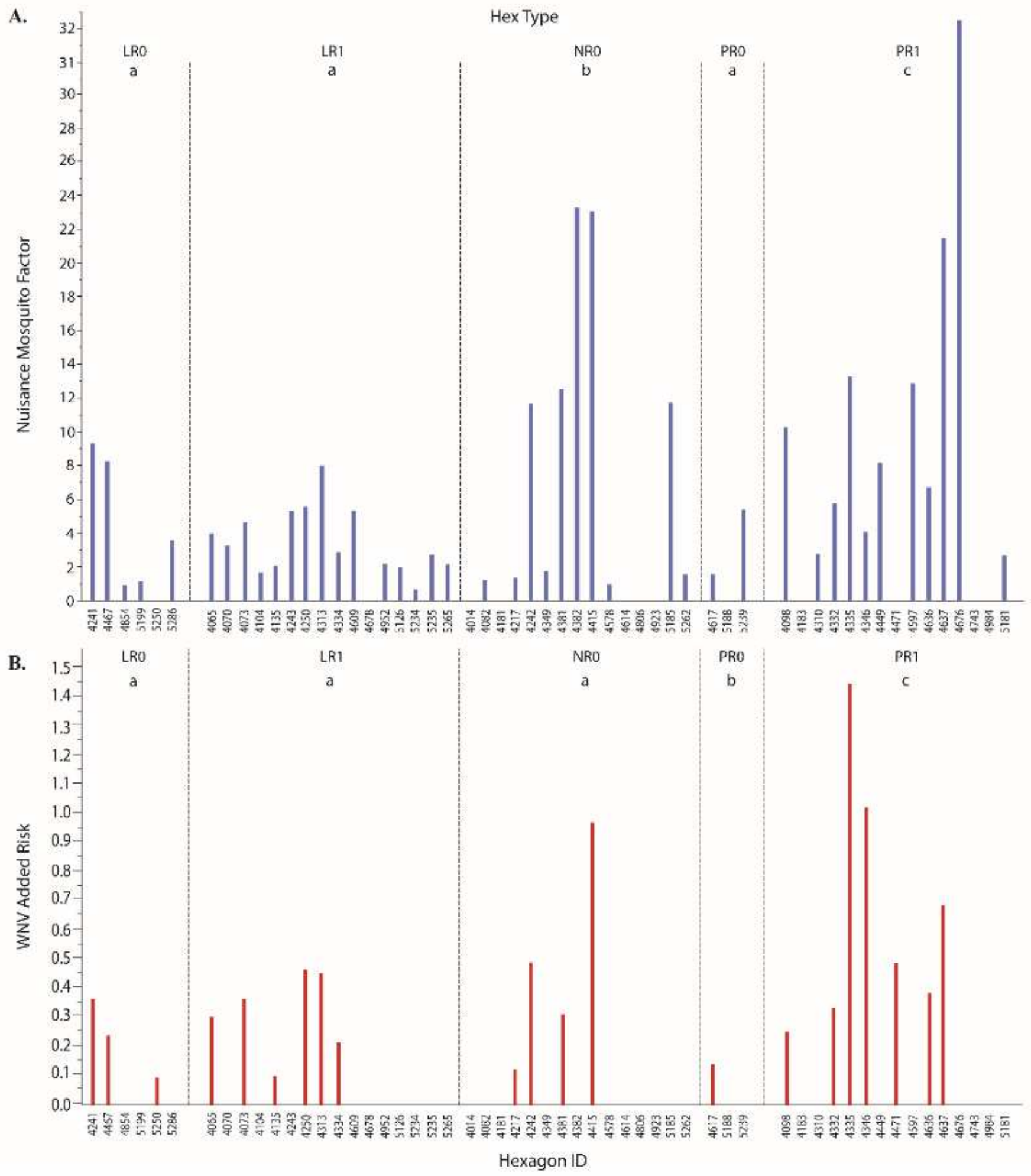

Figure 5

Relationship of each of the 55 UFS study hexagons ( $y$-axis = unique identification number) by nuisance mosquito factor $(A)$ and human WNV added risk (B). Letters above each box and whisker plot designate significantly different groups by hexagon type, as calculated by Tukey's HSD.

\section{Supplementary Files}


This is a list of supplementary files associated with this preprint. Click to download.

- graphicalabstract.tif

- Additionalfile1.docx 